\section{University of Nottingham}

UK | CHINA | MALAYSIA

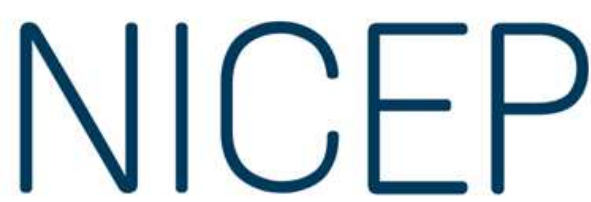

Nottingham Interdisciplinary Centre for Economic and Political Research

NICEP Working Paper: 2020-04

\title{
Christian missions and anti-gay attitudes in Africa
}

\section{Maxim Ananyev and Michael Poyker}

Nottingham Interdisciplinary Centre for Economic and Political Research https://nicep.nottingham.ac.uk

School of Economics and School of Politics and International Relations, University Park, Nottingham, NG7 2RD 


\title{
Christian Missions and Anti-Gay Attitudes in Africa*
}

\author{
Maxim Ananyev $^{\dagger}$ and Michael Poyker ${ }^{\ddagger}$
}

November 7, 2020

\begin{abstract}
We argue that colonial Christian missions had a long-term impact on anti-gay attitudes in Africa. We use a geo-coded representative survey of African countries and the location of historical Christian missions to estimate a significant and economically meaningful association between proximity to historical missions and anti-gay sentiments today. Using anthropological data on pre-colonial acceptance of homosexual practices among indigenous groups, we show that the establishment of missions, while nonrandom, was exogenous to pre-existing same-sex patterns among indigenous population. The estimated effect is driven by persons of Christian faith and statistically indistinguishable from zero on samples of Muslims, nonbelievers, and followers of traditional indigenous religions. Thus, we argue that our results are indicative of a causal effect of missionary religious conversion to Christianity.
\end{abstract}

Keywords: Missions, Africa, Tolerance, Homosexuals, Religion.

JEL codes: J15, N37, Z1

\footnotetext{
${ }^{*}$ We are grateful to Victoria Baranov, Augustin Bergeron, Ashley Blum, Paola Giuliano, Pauline Grosjean, Sergei Guriev, Morgan Kelly, Daniel Posner, Yuan Tian, Nico Voigtländer, Romain Wacziarg, and conference participants at AASLE, ASREC, NEUDC, and OzClio for excellent suggestions. We are grateful to Valeria Rueda who generously provided historical mission data and to Matthias Kroenke who generously provided geo-coded Afrobarometer data. Poyker is grateful for financial support from the Institute for New Economic Thinking. All errors are ours. Correspondence at: Sir Clive Granger Building B33, School of Economics, University of Nottingham, University Park, NG7 2RD, Nottingham, UK.

${ }^{\dagger}$ Ananyev: University of Melbourne; e-mail address: maxim.ananyev@unimelb.edu.au

${ }^{\ddagger}$ Poyker: University of Nottingham; e-mail address: mikhail.poyker@nottingham.ac.uk
} 


\section{Introduction}

Christian missionary activity in Africa had substantial influence on development. Missions have been linked to an array of positive outcomes: education (Nunn et al., 2014), democracy (Woodberry, 2012), newspaper readership (Cagé and Rueda, 2016), and intergenerational mobility (Alesina et al., 2019) among others. Despite all those advantageous effects, however, given that major Christian doctrines opposed homosexuality, is it possible that missions have influenced a particular negative outcome: present-day anti-gay attitudes? In 33 African countries, surveyed by Afrobarometer, more than 70 percent of people would dislike to have gay persons as neighbors, while homosexuality is criminalized in more than half of countries of the region (Carroll, 2016).

Scholars of economic development only recently started to systematically explore the determinants of discriminatory attitudes towards LGBTQ+ persons (Baranov, De Haas and Grosjean, 2018, Brodeur and Haddad, 2018). This is an important line of inquiry because discrimination against people based on their race, gender, sexual orientation, and other characteristics is antithetical to prosperity. Thus, studying the roots of intolerance - including intolerance to LGBTQ+ persons is important for understanding multiple inequalities in the developing world. Anti-gay attitudes in Africa have been explained by the influence of the U.S. megachurches (Grossman, 2015) and political scapegoating of gay community during HIV / AIDS epidemic (Anthony, 2018). In this paper, we ask if even earlier events - arrival of Christian missions during the colonial period - could have influenced current attitude towards gay persons.

This is a uniquely suitable setting for this question, because - as we can demonstrate - the arrival of early Christian missions was unrelated to pre-colonial acceptance of homosexuality among indigenous groups, and rejection of homosexuality had been already an established norm within Christianity. We use three sources of data in this paper: (i) locations of the historical missions from Nunn (2010) and Cagé and Rueda (2016), (ii) the spatial data from the sixth Afrobarometer's wave that contains a question about intolerance toward homosexual persons (whether a respondent would oppose having homosexuals as neighbors), and, (iii) previously untapped for economic research, data on acceptance of homosexual practices among indigenous groups collected by Murray and Roscoe (1998). First, we measure exposure to historical missions as the minimum distance from missions to a village/town where the respondent lives. Then, using ordinary-least-squares (OLS) specification we estimate the effect of proximity to missions on hostility toward gay persons. In our preferred specification, we estimate that respondents located $100 \mathrm{~km}$ closer to a mission are 1.3 percentage points more likely to be intolerant to gay persons than those living farther away from a mission site. To put this number in the context, the distance to a mission varies from $0.1 \mathrm{~km}$ to $1400 \mathrm{~km}$. Thus our estimate can plausibly explain 19 percentage point variation in intolerance. Given that the average percentage of respondents who have anti-gay attitudes is 63.8, the effect of missions is substantial.

This estimate can be interpreted causally if the locations of the missions are exogenous to counterfactual levels of intolerance. Given that the locations of the missions were nonrandom (Jedwab, zu Selhausen and Moradi, 2019), causal identification can be challenging. However, we use anthro- 
pological data on pre-colonial levels of acceptance of homosexual practices (Murray and Roscoe, 1998) to demonstrate that there is no discernible relationship between pre-colonial acceptance of homosexuality and locations of the missions. We also consider a set of other potential violations of identification assumptions. Specifically, we test if geographical determinants of locations of missions (e.g., terrain ruggedness and proximity to coast) could have influenced modern levels of intolerance directly or indirectly (through economic development, polygyny practices, HIV prevalence, literacy, and etc.).

Our results do not depend on the functional form of the minimum distance-to-mission, hold if we use the number of missions in respondent's vicinity as an alternative measure of exposure to historical missions, and are robust to the alternative measures of the dependent variable. In the baseline specification, we only control for the exogenous geographic factors and the set of country, ethnicity, and ethnic homelands fixed effects. In other specifications, we control for a rich set of individual-level variables (education, various proxies for living conditions, employment) and community-level variables (population density and luminosity from satellite images). Our results are not driven by any single country or a set of countries.

We argue that the most plausible channel of influence of colonial Christian missions on modern anti-gay intolerance is religious conversion. It has been demonstrated by Nunn (2010) that the missions were effective in promoting Christian faith among the indigenous population. However, the missions also promoted literacy and provided medical care. We contend that it is plausible that it is precisely the spread of religion (not education or medical practices) that influenced modern antigay attitudes. We offer two main pieces of evidence: first, our subsample analysis shows that the effect is entirely driven by Christian respondents, and, second, the effect persists if we control for individual-level and community-level potential consequences of missionary activity (education, material conditions, democratic values). It is also worth pointing out that the secular potential consequences of missionary activity most likely lead to more tolerance, not less. Thus these concerns probably attenuate our estimates. We also find that our main estimate remains significant if we exclude Evangelical respondents, or look only at the subsample of Catholic respondents, thus ruling out the possibility that the effect is entirely driven by modern U.S. "megachurches" (though they were important in promoting values of the U.S. Evangelical movement, including rejection of homosexuality).

Conceptually, the definition of homosexuality used in this paper refers to the same-sex attraction that can by a part of a wide variety of LGBTQ+ identities. It should be noted, however, that in Christianity the stigma attached to male-to-male attraction appears to be more prominent. Specifically, it is often interpreted to be explicitly prohibited in the Old Testament and in the New Testament, while female-to-female attraction is prohibited only in the New Testament. ${ }^{1}$ Relatedly, colonial-era laws enacted in British colonies explicitly copied many features of British "anti-sodomy" legislation. It is also worth pointing out that anthropological data collected in Murray and Roscoe (1998) is noisier when in tomes to female homosexuality. ${ }^{2}$ While discrimination

\footnotetext{
${ }^{1}$ See more detailed discussion in Section 2.

${ }^{2}$ See discussion in Section 3.
} 
against LGBTQ+ persons is not limited to men, these features of the context and the data make our study more informative about the roots of intolerance to male homosexuality than to female homosexuality.

We build on significant body of literature in the field of African studies that analyzes the causes of the intolerance toward homosexuality in Africa. Previous studies (e.g., Awondo, Geschiere and Reid, 2012, Currier, 2018) argued that anti-gay sentiments were driven by a number of factors including consolidation of power by elites, anti-elite resentment, conspiracy theories, secret societies, witchcraft, and religion. However, this literature only considered how contemporaneous religiosity affects these sentiments. For example, Awondo, Geschiere and Reid (2012) suggest that anti-gay discourse in Uganda was largely facilitated by American conservative Christians who had access to the high levels of government, while Thoreson (2014) emphasize the influence of Christian nationalism. Anti-homosexual attitudes in Zambia were explored by Klinken (2014) who linked anti-gay attitudes to Pentecostal Christianity that influences national identity. These studies offer rich qualitative analysis of contemporary institutions and anti-homosexuality in specific countries. Our paper complements this body of work by bringing a long-term view on the problem and conducting an empirical analysis of the impact of colonial Christian missions on modern anti-gay attitudes in 33 African countries.

Our study is also relevant to literature on the legacies of Christian missions in Africa. Scholars have argued that the missions had positive effects: promoting democracy (Woodberry, 2012), contributing to printing and written tradition (Cagé and Rueda, 2016), reducing early marriages (Kudo, 2017), improving intergenerational mobility (Alesina et al., 2019), increasing the scope of cooperation (Bergeron, 2020), and persistence in development (Nunn, 2010, and Valencia Caicedo, 2019). Only one recent study (Cagé and Rueda, forthcoming) show negative effect of missions on HIV / AIDS instances. We show that missionary activity was not always beneficial but also had a very persistent and large effect on intolerance toward gay persons, possibly influencing the criminalization of homosexuality in many African countries.

The economic literature has established several important historical determinants of current values and attitudes: pre-industrial economic conditions (Alesina, Giuliano and Nunn, 2013), biased gender ratios (Baranov, De Haas and Grosjean, 2018,Grosjean and Khattar, 2019), slavery (Nunn, 2008), and ancestral political autonomy (Michalopoulos and Papaioannou, 2013). ${ }^{3}$ In particular, related to the LGBTQ+ people, Baranov, De Haas and Grosjean (2018) show that malebiased gender ratios influenced opposition to same-sex marriage in Australia as well as occupational segregation by gender, while Brodeur and Haddad (2018) argue that in California during the Gold Rush high male-to-female ratio caused more tolerant attitudes towards homosexuality, Bentzen and Sperling (2020) showed that "faith-based initiatives" in the U.S. promoted scepticism towards homosexuality, towards science, and towards female empowerment. Here, we demonstrate how colonial institutions and religious doctrines shaped attitudes of the indigenous African

\footnotetext{
${ }^{3}$ The norms ans values themselves have been shown to impact economic development. Some examples of such studies are: Zak and Knack (2001), Algan and Cahuc (2010), Nunn and Wantchekon (2011), Alesina and Giuliano (2015), and Mokyr (2016).
} 
population, reverting their attitudes toward homosexual persons. ${ }^{4}$

The paper proceeds as follows. In Section 2, we provide background about historical and contemporary attitudes toward homosexuals in Sub-Saharan Africa and explains attitudes of Abrahamic religions towards homosexuality. Section 3 introduces our data sources. Section 4 provides empirical specification, results, and discuss our identifying assumptions. Section 5, in turn, discusses the mechanisms and provides evidence in favour of the spread of Christianity as the main factor. Section 6 concludes.

\section{Historical Background}

Indigenous groups of Sub-Saharan Africa are documented to have been tolerant to homosexual relationships. Early European scholars and travelers to the region reported many instances of overt homosexuality and cross-dressing among men. Andrew Batell, an English explorer, who had been imprisoned in the 1590s by the Portuguese in the territory of modern Angola, wrote about the practices among the Imbalanga: "They have men in women's apparel, whom they keep among their wives." Later, Sir Richard Burton, researching the Portuguese sources from the 16th century found observations of the instances of male homosexuality among the Kongo tribe (Epprecht, 2006). A more systematic anthropological record confirmed those early observations. Acceptance of homosexual marriages has been documented among the indigenous groups of Southeast Nigeria (Nwoko, 2012) as well as among 40 ethnic groups across Sub-Saharan Africa (Narrain et al., 2018). Summarizing the scholarship on indigenous African homosexuality, Nigerian gay rights activist Bisi Alimi wrote "If you say being gay is not African, you don't know your history." 5

Anthropological literature (De Rachewiltz, 1964, Herdt, 1991, and Epprecht, 2008) documents that indigenous populations of Sub-Saharan Africa were not intolerant to homosexuals. Specifically, Murray and Roscoe (1998, p.280) list 56 African ethnic groups with pre-colonial same-sex patterns. In some of those groups, we see a stark reversal of the attitude following European colonization. For example, if we look at one of these groups, Gikuyu/Kikuyu in Kenya, that was accepting same-sex relationship (and even had a term for gay persons, onek, that can be translated as "active male" Murray and Roscoe, 1998, p.218), now 95\% of the Afrobarometer respondents of that ethnic groups are Christian and $84.5 \%$ of them report a high level of intolerance to homosexuals (according to our baseline measure). Another example is the Pangwe/Pahouian (Fang) ethnic group in Gabon where gay men were caller a bele nnem e bango ("he has the heart [aspirations] of boys" Murray and Roscoe, 1998, p.219). Now 90\% of respondents from this ethnic group are

\footnotetext{
${ }^{4}$ Our study also contributes to the growing discussion on how religion affects various social and economic outcomes. Many studies in this field explore the impact of religion on economic growth (Barro and McCleary 2003, Rubin 2017), human capital accumulation (Carvalho and Koyama (2016), Chaney (2019) among others), earnings and labor supply (Tomes 1984, Van Hoorn and Maseland 2013), suicide (Becker and Woessmann 2018), and formation of beliefs and religious identities (Gershman 2015, Binzel and Carvalho 2017, Carvalho 2019). See Carvalho, Iyer and Rubin (2019) for a recent systematic review. Our results in this paper suggest that religion can also serve as a powerful source of change and persistence of norms and beliefs.

${ }^{5}$ The Guardian, Sep 9, 2015. If you say being gay is not African, you don't know your history. www . theguardian . com/commentisfree/2015/sep/09/being-gay-african-history-homosexuality-christianity.
} 
Christian and $83 \%$ report a high level of intolerance to homosexuals.

When it comes to the indigenous attitudes to homosexuality in Africa, Murray and Roscoe (1998) do not find evidence of public anti-gay attitudes. In fact, it is noted that "homophobia... is a western import" (Kendall, 1998). ${ }^{6}$ For some groups without evidence of homosexual practices, (Murray and Roscoe, 1998, p. 209) say that "absence of evidence can never be assumed evidence of absence." The same-sex practices are not always shared with outsiders (Gaudio, 1998). For the purpose of our estimations, however, the absence of publicly acknowledged and practiced samesex relationship is sufficient because the missionaries were unlikely to observe private practices as well. If they were choosing locations in part based on the acceptance of homosexuality among indigenous groups, they would have taken into account public same-sex practices or their absence. ${ }^{7}$

Traditional Abrahamic religions (Judaism, Christianity, Islam) have been traditionally less accepting of homosexuality. The sacred texts of these religions (The Torah, The Bible, The Qur'an) have passages that in different points in time were interpreted as a prohibition of homosexuality. Specifically, The Code of Holiness (Leviticus 17-26) identifies male homosexuality as a sin punishable by death ("Do not have sexual relations with a man as one does with a woman; that is detestable." (Lev: 18:22)). ${ }^{8}$ The Epistle to the Romans in The New Testament has been interpreted as a prohibition of both male and female homosexuality ("Because of this, God gave them over to shameful lusts. Even their woman exchanged natural sexual relationship for unnatural ones. In the same way the men also abandoned natural relations with women and were inflamed with lust for one another." (Romans 1:2627)). ${ }^{9}$ This view is also echoed in the Epistle 1 to Corinthians ("Or do you not know that wrongdoers will not inherit the kingdom of God? Do not be deceived: Neither the sexually immoral nor idolaters nor adulterers nor men who have sex with men." (1 Corinthians 6:9-10)). Qur'an also has verses that have been interpreted as a prohibition of homosexuality ("Indeed, you approach men with desire, instead of women. Rather, you are a transgressing people." (Qur'an 7:81)). ${ }^{10}$

These passages from the sacred texts were used later to justify the rejection of homosexual relationships. Influenced by The Bible and early Christian teachings, Roman Christian emperors prescribed the death penalty to those who committed homosexual acts. ${ }^{11}$ Intolerance to homosexuals has been inherited by all major Christian denominations. Rejection of homosexual practices is a part of the 1992 Catechism of the Roman Catholic Church. ${ }^{12}$ While many Protestant denominations now do accept homosexuality, allow gay clergy, and offer blessings for same-sex marriage, this is a relatively recent phenomenon. Martin Luther called homosexuality "monstrous depravity" (Pelikan, 1958). In 2003, an appointment of an openly gay bishop in New Hampshire caused

\footnotetext{
${ }^{6}$ This particular passage refers to Lesotho, but it reflects the situation in other countries as well.

${ }^{7}$ As we discuss in Section 4.3.1, we find no evidence of that.

${ }^{8}$ Quotes from the Bible are given according to the New International Version (NIV) published on Bible Gateway: www. biblegateway.com/.

${ }^{9}$ Some scholars insisted that this particular passage condemns heterosexual individuals who commit homosexual acts, while others argue that those verses are influenced by the Code of Holiness and should be interpreted as an unambiguous view that homosexuality violated God's order.

${ }^{10}$ Sahih International Translation. The Quranic Arabic Corpus. http: / / corpus . quran. com/.

${ }^{11}$ See, for example, Codex Theodosianus, that requires homosexuals to be subjected to "avenging flames."

${ }^{12}$ See line 2396. http: / / www. vatican.va/archive/ENG0015/_P88.HTM.
} 
deep divisions within the Anglican Communion, when the group of conservative American bishops threatened to leave the Episcopal Church. ${ }^{13}$ The Protestant community remains divided on the issue of same-sex marriage with some groups accepting it and some groups opposing it.

The earliest Christian communities in Sub-Saharan Africa appeared in Ethiopia in the 4th century. Early missionary work in Sub-Saharan Africa has been done by the Portuguese in the 16th century. Later, with the rise of European trade and colonial expansion, missions from Germany, Belgium, France, and Great Britain appeared on the continent (Zandt, 2011). The main purpose of missions was the religious conversion of indigenous groups to Christianity. The conversion was significantly aided by goods and services offered within the missions - most notably, education and health care (Nunn, 2010). As Nunn et al. (2014) point out, the locations of Christian missions were not random. The most important factors were access to clean water, mild climate, and proximity to European trade routes.

The anti-gay attitudes among the public can be traced back to colonialism. An important norm imported by the European colonizers was "silence" in the aspects related to sex (Kaoma, 2018 attributes it to "Victorian" culture). Another important cultural feature promoted by the colonizers was "heterosexual nuclear family" that was deemed important for agricultural production (Bosia, 2014). Thus, the queer traditions of Africa's pre-colonial past were silenced, denounced, and gradually supplanted by heteronormativity. In post-colonial times, the Christian missions continued to play an important role and influence governments of the newly independent states by leveraging their connection to international donors. In many places, missions were in charge of infrastructural projects, healthcare, education, with local bishops essentially playing the roles of chiefs (Maxwell, 2000). Thus, post-colonial developments in many aspects did not reduce the ideological influence of colonial missions.

The politicization of homosexuality by political elites is often understood as a relatively recent phenomenon. Robert Mugabe started the trend of a nation's leader speaking against gay persons in 1995, to be later followed by leaders of Uganda and Kenya (M'Baye, 2013). Today, several countries of Sub-Saharan Africa have harsh anti-gay legislation. According to Amnesty International, in Uganda, those found to be involved in a same-sex relationship can face seven years in prison. The Same-Sex Marriage Prohibition Act in Nigeria, signed into law by then-President Goodluck Jonathan in 2014 punishes homosexual meetings and clubs by more than 10 years of prison. ${ }^{14}$ Homosexuality is also illegal in Cameroon, Kenya, Tanzania, Zambia, and 24 other countries in Sub-Saharan Africa. These legislations are often supported by rhetoric that juxtaposes protection of "God's design" with the alleged influence of "Western groups." ${ }^{15}$ People's "religious inclinations"

\footnotetext{
${ }^{13}$ See The Guardian, Sep 14, 2003. Anglicans Face Schism Over Gay Row. www • theguardian • com/uk/2003/sep/ 14/religion.world.

${ }^{14}$ The Associated Press, “Nigeria president Goodluck Jonathan bans gay meetings," Jan 13, 2014, www.cbc.ca/ news/world/nigeria-president-goodluck-jonathan-bans-gay-meetings-1.2495376.

${ }^{15}$ See, for example, a 2014 speech by President of Uganda: "It seems the topic of homosexuals was provoked by the arrogant and careless Western groups that are fond of coming into our schools and recruiting young children into homosexuality and lesbianism, just as they carelessly handle other issues concerning Africa." (Daily Monitor, "President Museveni's full speech at the signing of Anti-Homosexuality bill," Feb 4, 2014, www.monitor.co.ug/News/National/ Museveni-s-Anti-Homosexuality-speech/688334-2219956-4xafil/index.html.)
} 
have been cited by Nigerian officials to justify the anti-gay legislation.

Another religion important to understanding homosexuality in Africa is Islam. Islam first arrived to Africa in the 7th century via conquest of North Africa and later spread further to the South through Transsaharan trade, migration, and religious conversion of the ruling classes (Robinson, 2004). Now Muslims often do support anti-gay policies on par with many Christian groups. For example, in Senegal, local imams were on the forefront of a campaign against a supposed gay marriage in 2008 (M'Baye, 2013). In Nigeria, leaders of the Muslim communities supported gay marriage prohibition similarly to the leaders of Christian communities (Oguntola-Laguda and van Klinken, 2016). According to Anderson (2007), "not only much of Christianity and Islam independently denounce homosexuality, their trans-religious concurrence combines with an unusually susceptible audience to create a formidable anti-gay force." While Islam is arguably not less important for understanding anti-gay attitudes in many African countries than Christianity, our study is focused on the effect of Christian missions. ${ }^{16}$

The idea that the criminalization of homosexuality by the African governments and anti-gay attitudes by the public are partly caused by Western religious expansion — specifically by the U.S. megachurches - has been proposed by journalists, activists, and scholars. Specifically, Cheney (2012) argues that U.S. Evangelicalism was an important source of influence on the anti-gay legislation in Uganda, and Grossman (2015) shows that the LGBT salience is related to the growth of Pentecostal, Renewalist, and Evangelical communities. It has been also suggested that the humanitarian response of George W. Bush administration to HIV/AIDS problem, that emphasized abstinence and faith-based approach, contributed to the proliferation of anti-gay legislation and attitudes (Anthony, 2018). Kaoma (2018) advanced the notion of "Christian-informed protective homophobia" that occurs when the protection of "traditional values" promoted by the Vatican and the U.S. Christian Right coalesces with the desires to protect African cultural identity from globalization. According to Valois (2016), accusations of homosexuality are used as markers of "inauthenticity" in competition between different churches in Uganda. Among many thorough case studies, the influence of Pentecostalism on homophobia in Zimbabwe is highlighted by Connor (2011), while the influence of Pentecostalism in Cameroon is analyzed by Lyonga (2016).

In this paper, while we do not disagree with the role of modern churches and political movements, we contend that the roots of intolerance towards homosexuals might also lie in the European colonialism of the 19th century and early Catholic and Protestant missions. To the best of our knowledge, ours is the first quantitative study of the long-term effect of European colonial religious missions on anti-gay attitudes.

\footnotetext{
${ }^{16}$ In Appendix Table A.1 we show positive correlation between Islam and current level of intolerance toward gay people.
} 


\section{Data}

Data on Intolerance and other Individual Characteristics The individual data on anti-gay attitudes among the population comes from the sixth (2016) wave of the Afrobarometer survey. ${ }^{17}$ Each country's survey contains 1,200 to 2,400 respondents and is a representative cross-section of all citizens of voting age. We use this particular wave because out of six waves of Afrobarometer, the question regarding attitude toward gay persons was asked only in this one. ${ }^{18}$

The main variable of interest is intolerance to homosexuals (Intolerance ${ }_{i}$ ). We construct it as an indicator variable by using the following question: "... Would [you] like having people from this group [Homosexuals] as neighbours, dislike it, or not care?" These are the possible answers: (i) Strongly dislike, (ii) Somewhat dislike, (iii) Would not care, (iv) Somewhat like, (v) Strongly like, or (v) Don't know. If a respondent answered that they strongly dislike having gay neighbours, we assign the value of 1 to the Intolerance $_{i}$ and 0 otherwise. ${ }^{19}$ Approximately $0.07 \%$ of all observations are missing and we omit these observations. In addition, $1.41 \%$ of the respondents answered "don't know." We consider these observations as zeroes; however, all results hold if we omit them. ${ }^{20}$

This is the only question on anti-gay attitudes available in Afrobarometer. It is limited in scope, since it asks only about residential preferences and not, for example, about labor market discrimination (whether the respondent would hire a gay person) or political preferences (whether the respondent would vote for a gay person). It is quite unlikely, however, that anti-gay sentiments this question registers are confined solely to residential preferences and do not translate to other areas. Another potential problem is social desirability bias. Given that homosexuality is politicized in many African countries in various ways, it is possible that people feel pressured to provide a particular answer. The direction of the pressure could be different in every country depending on the nature of politicization of homosexuality. To address this concern, we include country fixed effects in all our specifications to control for country-level pressures, so if everyone's reported opinion on homosexuality is shifted by the same amount due to the country-level legislation, the bias should be netted out by the country fixed effect.

We also use a set of additional demographic and socioeconomic variables from Afrobarometer: e.g., gender, age, religion, ethnicity, education, employment, access to public goods (water, toilet, and electricity), and household assets.

\footnotetext{
${ }^{17}$ Available here: https://afrobarometer.org/data/merged-round-6-data-36-countries-2016.

${ }^{18}$ We also obtained new, seventh (2019), wave of the Afrobarometer survey with GPS coordinates (available here: https://afrobarometer.org/data/merged-round-7-data-34-countries-2019). It is similar to the sixth wave and also contains the question about anti-gay attitudes. We use it to show that our baseline results hold when we use a different dataset.

${ }^{19}$ In Section 4 we also use two alternative measures of intolerance. One is also a dummy, equal to one if a respondent answered that they strongly dislike or somewhat dislike having gay neighbours, and 0 otherwise. Another is the ordinal variable ranging from 0 (respondent strongly like to have gay persons as a neigbours) to 4 (respondent strongly dislikes having gay neighbours). The former measures a less extreme level of intolerance toward gay persons, and the latter measure the extent of intolerance. In our sample, $63.83 \%$ of the respondents strongly dislike having gay neighbours and $8.11 \%$ somewhat dislike it. See the distribution in Figure C.1.

${ }^{20}$ We checked whether a dummy for missing or "don't know" observations is correlated with the distance to historical missions. We did not find any significant correlation.
} 
Overall, our sample spans 33 African countries: Benin, Botswana, Burkina Faso, Burundi, Cameroon, Cape Verde, Eswatini (Swaziland), Ivory Coast, Gabon, Ghana, Guinea, Kenya, Lesotho, Liberia, Madagascar, Malawi, Mali, Mauritius, Morocco, Mozambique, Namibia, Niger, Nigeria, Saint Thomas and Prince, Senegal, Sierra Leone, South Africa, Tanzania, Togo, Tunisia, Uganda, Zambia, and Zimbabwe. ${ }^{21}$ Following Nunn (2010), we omit from the sample respondents that are not of African descent. Figure C.2 reports countries' average level of intolerance toward gay people.

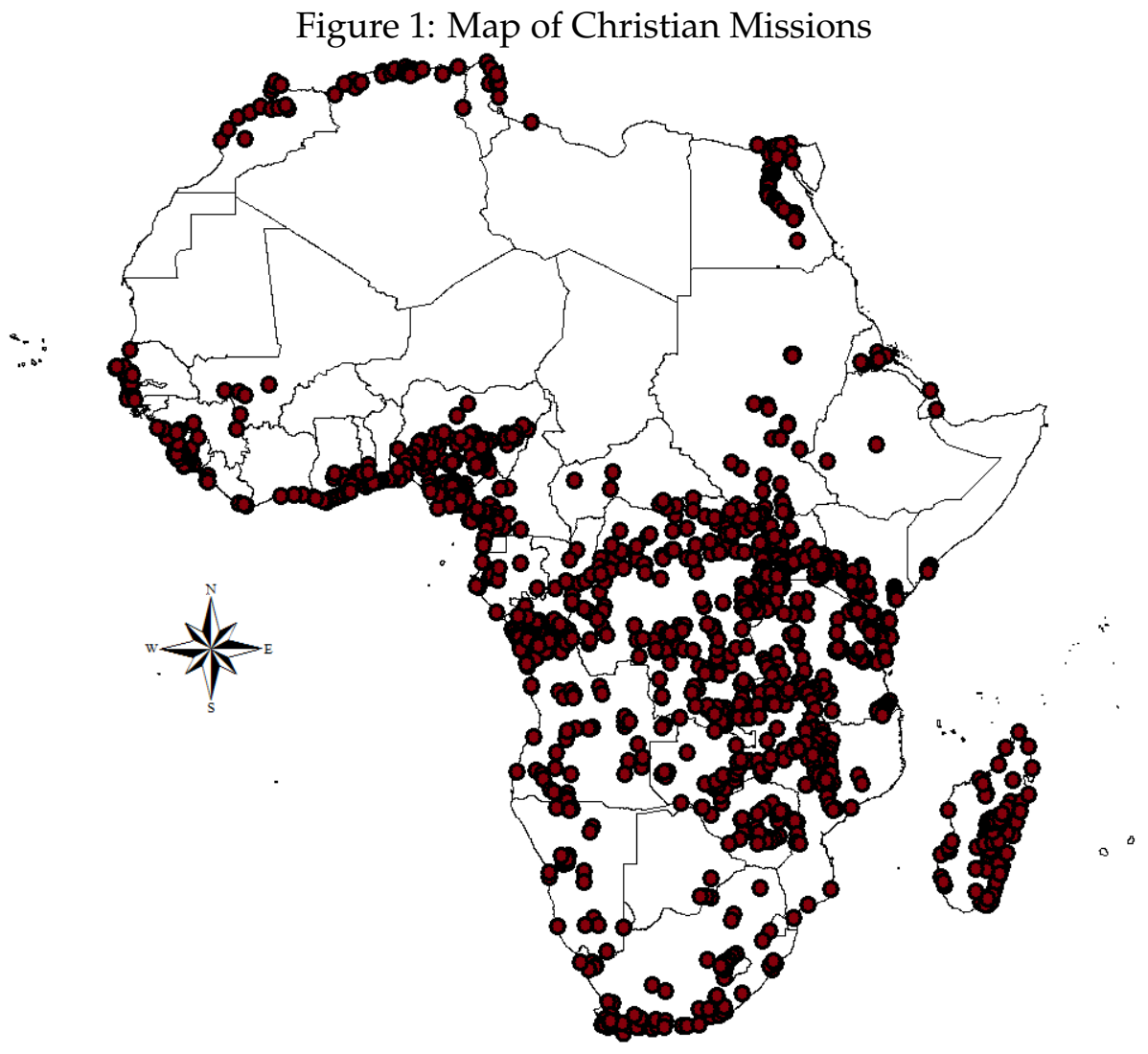

Source: Missions data from Nunn (2010).

Data on Historical Missions Historical mission data comes from Nunn (2010). It contains 1321 mission locations with coordinates and the denomination of Christianity they belong to (see Figure 1). This dataset is the most popular in the literature studying effects of European colonization and missions on African institutions and development. The dataset represents an ESRI shapefile that contains latitude and longitude of the historical missions. We compute the minimum distance (in $\mathrm{km}$ ) between each respondent of the Afrobarometer survey and the nearest mission. To explore the robustness of our estimates, we also compute alternative functional forms of the minimum distance and the number of missions within a certain radius of the respondent. As missions' data

\footnotetext{
${ }^{21}$ The sixth Afrobarometer's wave has 36 countries; however, the question about the tolerance toward gay persons was not asked in Algeria, Egypt, and Sudan.
} 
differ in Nunn (2010) and in Cagé and Rueda (2016), for the sake of robustness, we also obtained raw data from Valeria Rueda and estimated our main specification using the explanatory variable calculated from this dataset as well.

Pre-colonial Attitudes Toward Homosexuality and Other Data The novel data on the pre-colonial attitudes toward homosexuals are coming from the anthropological study "Boy-wives and femalehusbands: Studies in African homosexualities," edited by Murray and Roscoe (1998). This book contains articles describing homosexual cultural norms in various African ethnic groups. In Appendix I "African Groups with Same-sex Patterns" of that book, there is a list of the 56 African ethnic groups that practiced any kind of same-sex relationship (see Figure C.3). We digitized and harmonized the name of those ethnic groups and matched them with our data. ${ }^{22}$

It is important to note that Murray and Roscoe (1998) document same-sex patterns and not necessarily just same-gender patterns. In many cases, acceptance of same-sex attraction is accompanied by patterns of cross-dressing and assuming nonconforming gender identities. ${ }^{23}$ Thus, the data can be used to assess not just traditional acceptance of homosexuality, but also - more broadly — as acceptance of wide array of LGBTQ+ identities and practices.

Regarding the difference between male and female homosexuality, Murray and Roscoe, 1998 make the best effort to document male and female same-sex patterns. ${ }^{24}$ They mention, however, an important limitation of their approach: female homosexuality is "infrequently revealed to men, especially outsiders." 25 Thus, we expect the data to be mainly driven by male homosexuality.

We also use ancestral data from Murdock's atlas and terrain data (ruggedness, elevation, night light luminosity, and population density) from Nunn and Puga (2012). We supplement our dataset with crop suitability data from Food and Agricultural Organization ${ }^{26}$ and malaria ecology from the Malaria Atlas Project. ${ }^{27}$

\section{Empirical Specification, Results, and Alternative Explanations}

In this section, we present our main specification, discuss assumptions under which our estimates show a causal effect of Christian missions on anti-gay sentiments, and evaluate the plausibility of these assumptions.

\footnotetext{
${ }^{22}$ Names of the ethnolinguistic groups in Murray and Roscoe (1998) and Murdock (1967) are mostly the same making matching straightforward. Table C.1 contains the crosswalk between the two.

${ }^{23}$ For example, Gaudio, 1998 describes the culture of yan daudu, individuals who are referred to by others as males but refer to each other using "feminine linguistic forms."

${ }^{24}$ For example, they specify separate notions for male and female homosexuality among Hausa and Mombasa.

${ }^{25}$ Preface, "All Very Confusing," page XXI.

${ }^{26}$ Global Agro-ecological Zones (GAEZ v3.0), available here: http: //www . gaez . i iasa.ac .at/.

${ }^{27}$ Available here: https: / / malariaatlas.org/.
} 


\subsection{Empirical Specification and Identification}

For our main specification, we use the following cross-sectional regressions where the observation is a respondent $i$ nested in village $v$ :

$$
\text { Intolerance }_{i(v, e)}=\alpha_{c}+\beta \cdot \text { Distance }_{v}+X_{i(v)} \Gamma+\lambda_{e}+\varepsilon_{i(v, e)},
$$

where Intolerance $_{i(v)}$ is the dummy variable equal to 1 if a respondent would not like her neighbours to be gay, and Distance $v$ is a "treatment" variable equal to the minimum distance (in 100 $\mathrm{km}$ ) from respondent $i$ from the redvillage $v$ to the historical mission site. For the baseline specification, we do not add any controls to avoid post-treatment biases; however, we include geographic and socioeconomic pre-treatment controls $\left(X_{i(v)}\right)$ for robustness. We also include a set of ethnicity $\left(\lambda_{e}\right)$ and country fixed effects $\left(\alpha_{c}\right)$ Afrobarometer defines coordinates on the village/town level, thus all respondents located in the same village/town will have the same treatment. Thus, as the treatment is on the village level, we cluster standard errors on the village level as well.

The causal identification is based on the assumption that the location of historical missions is (i) not impacted by the pre-colonial homosexual behaviors and (ii) not impacted by the unobservable factors that made the establishment of the historical mission more likely and affected future intolerance. In the baseline specification, by using ethnicity fixed effects we address the former concern. In addition, in Section 4.3.1 we also check that historical missions were not strategically placed in homelands of ethnic groups with same-sex practices. We address potential violations of the latter assumptions in Section 4.3.2 where we introduce additional individual and geographic controls and fixed effects, and consider other alternative scenarios.

\subsection{Core Results}

Panel A of Table 1 reports our main results: respondents living closer to the historical missions are more likely to dislike having gay neighbors. The estimate from Column I suggests that a respondent living farther away from a mission will be less intolerant than one living next to the mission. This specification includes only country fixed effects; hence, identifying variation is the within-country minimum distance to the mission. We also absorb all institutional factors thus severing the effect of missions on anti-gay sentiments through the national institutions. Columns II-V scrutinize the robustness of this pattern to the inclusion of various controls and fixed effects. Column II introduces contemporary geographic controls (ruggedness, elevation, and coordinates). Column III controls for respondents' exogenous characteristics (gender, age, and age squared). We control for urban status in Column IV. We add respondents' ethnicity fixed effects in Column $\mathrm{V}^{28}$ Our estimate holds throughout all columns. ${ }^{29}$ These results suggest, that historical missions

\footnotetext{
${ }^{28}$ The question about the respondent's ethnicity was not asked in Burundi and Tunisia (in total $4.6 \%$ of observations in our sample). We include those observations and also include a dummy equal to one if the ethnicity variable is missing in order not to lose observations. All the estimates remain significant if we omit these countries.

${ }^{29}$ We show the robustness of our baseline results to the alternative ways of computing standard errors. First, in Table C.3 we show that results remain significant if we cluster by country, province/state, or regional level (Columns
} 
have a large causal but reduced form effect on the tolerance toward homosexuals, such as people living closer to old missions appear to be less tolerant. The coefficient from the most conservative specification in Column V suggests that a respondent living $100 \mathrm{~km}$ farther away from the mission will be 1.3 percentage points less intolerant than one living next to the mission.

Table 1: Missions and anti-gay sentiments: Core results

\begin{tabular}{|c|c|c|c|c|c|}
\hline & I & II & III & IV & $\mathrm{V}$ \\
\hline Panel A: & \multicolumn{5}{|c|}{ Dependent variable: 1(Dislike homosexuals) } \\
\hline Min. distance-to-mission, $100 \mathrm{~km}$ & $\begin{array}{c}-0.007 * * \\
(0.0027)\end{array}$ & $\begin{array}{l}-0.005^{*} \\
(0.0028)\end{array}$ & $\begin{array}{l}-0.005^{*} \\
(0.0028)\end{array}$ & $\begin{array}{c}-0.008 * * * \\
(0.0028)\end{array}$ & $\begin{array}{c}-0.013 * * * \\
(0.0038)\end{array}$ \\
\hline R-squared & 0.256 & 0.256 & 0.259 & 0.260 & 0.282 \\
\hline Observations & 50,337 & 50,337 & 50,337 & 50,337 & 50,337 \\
\hline Panel B: & \multicolumn{5}{|c|}{ Dependent variable: 1(Dislike or somewhat dislike homosexuals) } \\
\hline Min. distance-to-mission, $100 \mathrm{~km}$ & $\begin{array}{c}-0.009 * * * \\
(0.0026)\end{array}$ & $\begin{array}{c}-0.006^{* *} \\
(0.0027)\end{array}$ & $\begin{array}{c}-0.006^{* *} \\
(0.0027)\end{array}$ & $\begin{array}{c}-0.010 * * * \\
(0.0027)\end{array}$ & $\begin{array}{c}-0.012 * * * \\
(0.0042)\end{array}$ \\
\hline $\begin{array}{l}\text { R-squared } \\
\text { Observations }\end{array}$ & $\begin{array}{c}0.256 \\
50,337\end{array}$ & $\begin{array}{c}0.256 \\
50,337\end{array}$ & $\begin{array}{c}0.259 \\
50,337\end{array}$ & $\begin{array}{c}0.260 \\
50,337\end{array}$ & $\begin{array}{c}0.282 \\
50,337\end{array}$ \\
\hline Panel C: & \multicolumn{5}{|c|}{ Dependent variable: Dislike homosexuals (ordinal, from 0 to 4 ) } \\
\hline Min. distance-to-mission, $100 \mathrm{~km}$ & $\begin{array}{c}-0.023^{* * *} \\
(0.0068)\end{array}$ & $\begin{array}{c}-0.017 * * \\
(0.0069)\end{array}$ & $\begin{array}{c}-0.017 * * \\
(0.0068)\end{array}$ & $\begin{array}{c}-0.025 * * * \\
(0.0069)\end{array}$ & $\begin{array}{c}-0.029 * * * \\
(0.0099)\end{array}$ \\
\hline $\begin{array}{l}\text { R-squared } \\
\text { Observations }\end{array}$ & $\begin{array}{c}0.230 \\
50,337\end{array}$ & $\begin{array}{c}0.230 \\
50,337\end{array}$ & $\begin{array}{c}0.233 \\
50,337\end{array}$ & $\begin{array}{c}0.235 \\
50,337\end{array}$ & $\begin{array}{c}0.255 \\
50,337\end{array}$ \\
\hline Country FEs & $\checkmark$ & $\checkmark$ & $\checkmark$ & $\checkmark$ & $\checkmark$ \\
\hline Modern geo. controls & & $\checkmark$ & $\checkmark$ & $\checkmark$ & $\checkmark$ \\
\hline Demographic controls & & & $\checkmark$ & $\checkmark$ & $\checkmark$ \\
\hline Urban dummy & & & & $\checkmark$ & $\checkmark$ \\
\hline Ethnicity FEs & & & & & $\checkmark$ \\
\hline
\end{tabular}

Note: (a) Each panel reports on results of a one specification, run for each measure of intolerance toward homosexuals separately across all columns. (b) The dependent variable in Panel A is a dummy equal to 1 if the respondent answered that he/she strongly or somewhat strongly dislikes having gay neighbours and 0 otherwise. (c) The dependent variable in Panel B is a dummy equal to 1 if the respondent answered that he/she strongly dislikes having gay neighbours and 0 otherwise. (d) The dependent variable in Panel $\mathrm{C}$ is ordinal variable running from 0 (strongly like having gay neighbours) to 4 (strongly dislike having gay neighbours). (e) All regressions include constant. Modern geographic controls include ruggedness, elevation, and coordinates. Demographic controls include gender, age, and age squared. 33 country fixed effects, 295 ethnicity fixed effects. We add dummy for missing ethnicity if the question about ethnicity was not asked in that country (Burundi and Tunisia). (f) In parentheses we report standard errors clustered on geographical unit (village/town). 7,390 clusters. ${ }^{* * *} \mathrm{p}<0.01,{ }^{* *} \mathrm{p}<0.05,{ }^{*} \mathrm{p}<0.1$

Table C.7 demonstrates that our results are robust to various functional forms of the main explanatory variable: $\ln \left(\right.$ Distance $\left._{v}\right)$ in Column II, $\sqrt{\text { Distance }_{v}}$ in Column III, and quadratic poly-

II-IV). Second, we double-cluster standard errors (Cameron, Gelbach and Miller, 2011) by location and ethnicity in Column V to address that fact that intolerance toward gays can be ethnic-specific and by geographical unit and country, in Column VI, to address the fact that Afrobarometer surveys (and, thus, our dependent variable) were conducted on the country-level. Third, we also report spatial HAC (Conley, 2010) standard errors with different distance cutoffs to address possible spatial auto-correlation in Columns I-VI of Table C.5. Additionally, our results also hold if, in Table C.6, we aggregate the data at the country-ethnicity level. 
nomial in Column IV. ${ }^{30}$ Our results also hold if we use minimum distance along contemporaneous roads in Column $\mathrm{V}$ and minimum travel time in Column VI. ${ }^{31}$ In case there are several closely located missions, the minimum distance would underestimate the effect of proximity to the mission. Thus we report robustness of our results to the alternative measure of exposure to historical missions: number of missions in the $150 \mathrm{~km}$ and $300 \mathrm{~km}$ radius (Columns VII and VIII). ${ }^{32}$ Finally, we report results for our baseline measure using distances computed based on the mission data from Cagé and Rueda (2016) (Column IX) and results based on minimum distance to mission in either Cagé and Rueda (2016) or Nunn (2010) (Column X). Our results hold across all columns. Hereafter, we use the minimum distance-to-mission measure as the baseline measure.

We also obtain qualitativly identical results when we anti-gay sentiments from the newly released seventh wave of Afrobarometer in Panel A of Table C.8. In Panel B we pool the data from the sixth and seventh Afrobarometer waves and including the wave dummy replicate our baseline results from Table 1. Resulting coefficients appear to be more significant than when estimated separately by wave.

Our results are robust to alternative ways of measuring intolerance toward gay persons. In Panel B of Table 1, we define the dependent variable as a dummy equal to unity if respondents both "strongly dislikes" and "somewhat dislikes" having gay neighbours. And in Panel C we define it as an ordinal variable running from 0 (strongly like having gay neighbours) to 4 (strongly dislike having gay neighbours). The coefficient of interest appears to be significant in all columns. ${ }^{33}$

Our results are not driven by a particular subsample of the data. Column II of Table C.4 demonstrates the robustness of our results to the omission of the North African countries. Figure C.4 reports on the robustness of our preferred estimate in Panel A of Column V to dropping one country at a time. The estimated coefficient always remains significantly different from zero. Dropping Botswana, reduces the coefficient the most, from -0.013 to -0.018 . Dropping Cape Verde, increases the coefficient the most, from -0.013 to -0.011 .

\subsection{Robustness and Sensitivity Checks Assumptions}

\subsubsection{Missions Were Not Established in Places With Higher Pre-Colonial Levels of Intolerance}

As Murray and Roscoe (1998) document, before the arrival of European colonizers, indigenous groups in Sub-Saharan Africa differed in their attitude to homosexuality. One explanation of the results in Table 1 is that pre-colonial attitudes to homosexuality might influence both the locations of the missions and modern attitudes to homosexuality. Thus, the results in Table 1 could be spurious because of the confounding factor. Fortunately, Murray and Roscoe (1998) also contain

\footnotetext{
${ }^{30}$ We repeat our baseline specification from Column $\mathrm{V}$ of Table 1 for comparison. The quadratic term appears to be insignificant. Higher-order polynomials yield similar results.

${ }^{31}$ Here we use Google Maps application programming interface to construct minimum travel distance and travel time between a locality and its nearest mission.

${ }^{32}$ The results are robust to alternative thresholds.

${ }^{33}$ In the next Sections, we continue to use the measure from Panel A; however, all results hold for both alternative measures as well. Our results also hold if we use alternative weights in Column III of Table C.4.
} 
information on which indigenous groups practiced open homosexual relationships, and which groups did not. Here, we provide several pieces of evidence to address this concern.

First, we demonstrate in Panel A of Table 2 that pre-colonial acceptance of homosexual practices does not correlate with the anti-gay attitudes today. Column I shows a bivariate correlation which is not statistically significant, while Columns II-IV show the same relationship with different sets of controls. In none of the specifications, we find a statistically significant association between pre-colonial acceptance of homosexual practices and modern anti-gay sentiments.

Table 2: Ancestral homosexual practices do not correlate with anti-gay attitudes today and with distance to missions

\begin{tabular}{|c|c|c|c|c|c|c|}
\hline & $\mathrm{I}$ & II & III & IV & $\mathrm{V}$ & VI \\
\hline Panel A: & \multicolumn{6}{|c|}{ Dependent variable: Dislike homosexuals } \\
\hline $\begin{array}{l}\text { Ancestral norms allowed same- } \\
\text { sex relations }\end{array}$ & $\begin{array}{c}0.056 \\
(0.0470)\end{array}$ & $\begin{array}{c}0.057 \\
(0.0460)\end{array}$ & $\begin{array}{c}0.057 \\
(0.0460)\end{array}$ & $\begin{array}{c}0.079 \\
(0.0596)\end{array}$ & $\begin{array}{c}0.063 \\
(0.0509)\end{array}$ & $\begin{array}{c}0.080 \\
(0.0609)\end{array}$ \\
\hline Modern geo. controls & & $\checkmark$ & $\checkmark$ & $\checkmark$ & $\checkmark$ & $\checkmark$ \\
\hline Ancestral geo. controls & & & $\checkmark$ & & & $\checkmark$ \\
\hline Moralizing god & & & & $\checkmark$ & & $\checkmark$ \\
\hline Ancestral marital norms & & & & & $\checkmark$ & $\checkmark$ \\
\hline R-squared & 0.236 & 0.236 & 0.236 & 0.168 & 0.222 & 0.168 \\
\hline Observations & 50,337 & 50,337 & 49,141 & 32,717 & 43,939 & 31,191 \\
\hline Panel B: & \multicolumn{6}{|c|}{ Dependent variable: Min. distance-to-mission, $100 \mathrm{~km}$} \\
\hline $\begin{array}{l}\text { Ancestral norms allowed same- } \\
\text { sex relations }\end{array}$ & $\begin{array}{l}-0.770 \\
(0.6003)\end{array}$ & $\begin{array}{l}-0.760 \\
(0.5791)\end{array}$ & $\begin{array}{l}-0.760 \\
(0.5791)\end{array}$ & $\begin{array}{l}-1.018 \\
(0.7568)\end{array}$ & $\begin{array}{l}-0.837 \\
(0.6402)\end{array}$ & $\begin{array}{l}-1.046 \\
(0.7734)\end{array}$ \\
\hline Modern geo. controls & & $\checkmark$ & $\checkmark$ & $\checkmark$ & $\checkmark$ & $\checkmark$ \\
\hline Ancestral geo. controls & & & $\checkmark$ & & & $\checkmark$ \\
\hline Moralizing god & & & & $\checkmark$ & & $\checkmark$ \\
\hline Ancestral marital norms & & & & & $\checkmark$ & $\checkmark$ \\
\hline R-squared & 0.729 & 0.730 & 0.724 & 0.691 & 0.716 & 0.677 \\
\hline Observations & 50,337 & 50,337 & 49,141 & 32,717 & 43,939 & 31,191 \\
\hline
\end{tabular}

Note: (a) Each panel reports on results of a one specification, run for different dependent variables separately across all columns. (b) The dependent variable in Panel A is a dummy equal to 1 if the respondent answered that he/she strongly or somewhat strongly dislikes having gay neighbours and 0 otherwise. (c) The dependent variable in Panel B is the minimum distance (in $100 \mathrm{~km}$ ) from respondent $i$ to a historical mission. (c) All columns include country fixed effects, age, and female dummy. Modern geographic controls include ruggedness, elevation, and coordinates. Ancestral geographic controls include ancestral ethnic group's distance-to-coast, average ancestral ruggedness, and ancestral coordinates. Moralizing god is a dummy equal to one if respondent's ethnic group's ancestors had a high god present, active, and specifically supportive of human morality. Ancestral marital norms controls includes dummy for presence of preference for cousin marriages and polygamy. (d) Number of observations is decreasing because some control variables from Murdock (1967) are missing for some ethnic groups. All results hold if we add these observations with dummies for a missing observation. (e) In parentheses we report standard errors clustered on the geographical unit level (village $/$ town). ${ }^{* * *} \mathrm{p}<0.01,{ }^{* *} \mathrm{p}<0.05$, ${ }^{*} \mathrm{p}<0.1$

Secondly, we explore if there is a plausible connection between the location missions and pre- 
colonial acceptance of homosexual practices. The results of these tests are shown in Panel B of Table 2. In none of the specifications, the connection is statistically significant. This result is consistent with the literature on historical Christian missions that emphasized that the locations of missions were selected for logistical reasons (distance to coast, access to clean water etc.) and not by the traditions of local indigenous groups (Jedwab, zu Selhausen and Moradi 2019). At the same time, missions were not intentionally built around ethnic groups practicing same-sex relationships in order to "correct" ungodly behavior. ${ }^{34}$

Thirdly, in case we have measurement error in ethnic groups with same-sex culture that correlates with mission location it can invalidate our identification. Murray and Roscoe (1998) catalogued ethnic groups with same sex practices, thus it is safe to assume that those label as with same-sex patterns are labeled correctly. However, they could miss some, most likely small and thus less studied ethnic groups. To address, this issue we replicate Table 3 separately on the subset of the half of the largest and smallest ethnic groups. Here we assume that if large groups are more well-studied, their ancestral norms related to same-sex norms are defined with less measurement error. Table C.10 presents the results: coefficients in both subsamples are insignificant, suggesting that even for the sample of large, potentially more studies ethnolinguistic groups, ancestral norms allowing same-sex relations do not correlate with historical missions locations and current anti-gay sentiments.

Fourthly, in Table 3 we estimate the baseline regression (1) on two different subsamples: Column II presents the estimate on a subsample of individuals belonging to groups with open acceptance of homosexuality in pre-colonial times, and Column III shows the same regression for all the other groups. We find that the coefficients of association between the distance from the nearest mission and modern anti-gay sentiments are similar in both of these subsamples and close to the coefficient in our main regression in Table 1.

In Column IV, we introduce the interaction term $\beta^{H} \cdot$ Distance $_{v} \cdot 1$ (Same-sex culture) ${ }_{e}$; however, we do not find any heterogeneous effect of missions on ethnic groups with same-sex culture. Hence, it reinforces our conclusion that missions were not specifically targeting ethnic groups that exhibit tolerance to same-sex relationships.

To isolate the differential effect of missions, aside from adding the interaction between $\beta$. Distance $_{v}$ and the dummy for pre-treatment same-sex culture, in Column V, we replace $\beta$. Distance $v$ with $\beta^{N H} \cdot$ Distance $_{v} \cdot 1$ (No same-sex culture) $)_{e}$, so that our specification mirrors a split-sample estimation strategy in which the core estimation (1) would be run separately for respondents with and without same-sex culture, but at the same time imposes a common set of coefficients on other controls unrelated to ancestral attitudes to gay persons. ${ }^{35}$ Both coefficients appear to be negative and significant and while the coefficient for the effect of the mission proximity on ethnic groups with same-sex culture is larger in absolute value, the difference between the two coefficients is not significant ( $\mathrm{p}$-value $=0.308)$.

\footnotetext{
${ }^{34}$ As the treatment (ancestral norms) is computed on ethnicity level, in Table C. 9 we also replicate Table 2 on the ethnic homelands level instead of the respondent's level. None of the coefficient is significant at the conventional levels.

${ }^{35}$ The dummy for the same-sex culture is absorbed by the ethnicity fixed effects.
} 
Overall, we conclude, that (i) historical missions were not placed near ethnic groups that had some form of same-sex relationship and (ii) there is no differential effect of missions on respondents with different ancestral attitudes toward homosexuals.

Table 3: Ancestral homosexual practices: Subsample analysis

\begin{tabular}{|c|c|c|c|c|c|}
\hline \multirow[b]{3}{*}{ Sample } & $\mathrm{I}$ & II & III & IV & $\mathrm{V}$ \\
\hline & \multicolumn{5}{|c|}{ Dependent variable: Dislike homosexuals } \\
\hline & $\begin{array}{l}\text { Baseline } \\
\quad \text { (all) }\end{array}$ & $\begin{array}{l}\text { Had same- } \\
\text { sex culture }\end{array}$ & $\begin{array}{l}\text { No same- } \\
\text { sex culture }\end{array}$ & \multicolumn{2}{|c|}{ All } \\
\hline Min. distance-to-mission, $100 \mathrm{~km}$ & $\begin{array}{c}-0.0132 * * * \\
(0.0038)\end{array}$ & $\begin{array}{l}-0.018 * * \\
(0.0086)\end{array}$ & $\begin{array}{c}-0.011 * * * \\
(0.0043)\end{array}$ & $\begin{array}{l}-0.011 * * \\
(0.0043)\end{array}$ & \\
\hline $\begin{array}{l}\text { Min. distance-to-mission, } 100 \mathrm{~km} \\
\qquad \mathrm{x} \mathrm{w} \text { same-sex culture }\end{array}$ & & & & $\begin{array}{l}-0.009 \\
(0.0090)\end{array}$ & \\
\hline $\begin{array}{l}\text { Min. distance-to-mission, } 100 \mathrm{~km} \mathrm{x} \\
\text { Eth. groups w same-sex culture }\end{array}$ & & & & & $\begin{array}{l}-0.020 * * \\
(0.0082)\end{array}$ \\
\hline $\begin{array}{l}\text { Eth. Groups w/o same-sex cuture } \\
\qquad \Delta, \mathrm{p} \text {-value }\end{array}$ & & & & & $\begin{array}{l}-0.011 * * \\
(0.0043) \\
{[0.3080]}\end{array}$ \\
\hline $\begin{array}{l}\text { R-squared } \\
\text { Observations }\end{array}$ & $\begin{array}{c}0.282 \\
50,337\end{array}$ & $\begin{array}{l}0.232 \\
9,338\end{array}$ & $\begin{array}{c}0.287 \\
40,999\end{array}$ & $\begin{array}{c}0.286 \\
50,307\end{array}$ & $\begin{array}{c}0.286 \\
50,307\end{array}$ \\
\hline
\end{tabular}

Note: (a) In all columns, we take the most demanding specification from the baseline results, i.e., Column V in Panel A of Table 1. (b) In Column II, we estimate the specification for the subsample of respondents whose ethnic groups allowed same-sex relationships. (c) In Column III, we estimate the specification for the subsample of respondents whose ethnic groups did not explicitly allowed same-sex relationships. (c) Column IV adds interaction term $\beta^{H} \cdot$ Distance $_{v} \cdot 1$ (Same-sex culture) $)_{e}$. (d) Column V reports on specification (1) but replaces $\beta \cdot$ Distance $_{v}$ with $\beta^{H} \cdot$ Distance $_{v} \cdot 1$ (Same-sex culture) $)_{e}$ and $\beta^{N H} \cdot$ Distance $_{v} \cdot 1$ (No same-sex culture) $)_{e}$ (e) Dummy for the same-sex culture is absorbed by ethnicity fixed effects. (f) $\Delta$, p-value is the p-value for the difference between $\widehat{\beta}^{H}$ and $\widehat{\beta}^{N H}$. (g) In parentheses we report standard errors clustered on the geographical unit level (village/town). ${ }^{* * *} \mathrm{p}<0.01,{ }^{* *} \mathrm{p}<0.05,{ }^{*} \mathrm{p}<0.1$

\subsubsection{The Geographical Features of Missions' Location Did Not Make it Easier to Develop Intolerance to Homosexuality Later}

Locations of missions were undoubtedly influenced by geography. Specifically, as documented by Jedwab, zu Selhausen and Moradi (2019), missions were more likely to be located closer to the coast. And coastal cities are likely to have a high concentration of gay couples (Black et al., 2002). In addition, Dimico (2014) theorizes that rugged terrain mattered for the location of missions because it provided protection from military raids for the groups that have been selected by the missionaries for religious conversion. Also, according to Nunn and Puga (2012), rugged terrain hindered economic activity, and as long as lower levels of economic activity lead to less inclusive values (Inglehart and Welzel, 2005), ruggedness could have a causal impact on the current level of intolerance through economic development channel. One plausible alternative explanation for our results in Table 1 is that the same geographical characteristics that influenced locations of missions 
also influenced modern anti-gay sentiments.

We provide several pieces of evidence to alleviate this concern. Our results in Table 1 include an extensive set of geographic controls (including terrain ruggedness, elevation, and coordinates). As a robustness check, in Table C.4, we offer additional estimations that control for contemporary and geographic factors. Our results hold if in Columns IV and V, we include distance to the coast, distance to the capital, cereal and staple crop suitability controls. Column VI includes both fixed effects of the respondent and fixed effects of the ethnic groups that lived historically in those locations, absorbing all location-specific and respondent-specific ancestral characteristic. The inclusion of these controls does not change the result. Similarly, in Table C.12 we show that our results hold when we control for important for colonial economies cash crops and various determinants of malaria ecology. ${ }^{36}$ Similarly, the inclusion of these controls does not change the result. Thus, while it is possible that Christian missions were established in places that could have made gradual development of anti-gay sentiments, these potential confounding factors are unlikely to influence our main result.

A specific causal pathway through which geography could possibly matter for the missions and for current anti-gay sentiments is through its impact on number HIV/AIDS cases. Many countries of Sub-Saharan Africa suffered severely from the HIV/AIDS epidemic in the 1990s. It has been demonstrated that the HIV/AIDS prevalence might increase intolerance towards gay people because, among heterosexuals, HIV / AIDS is associated with homosexuality and bisexuality (Herek and Capitanio, 1999), Thus, if the geographical determinants of the location of religious missions overlapped with the determinants of HIV/AIDS cases, then the estimates of the effects of missions on anti-gay sentiments might be spurious. There are at least two causal pathways that might lead to spurious results: the first one operates through current poverty, and the second one operates through polygamy.

Scenario 1: Ruggedness and Poverty Missions were more likely to be located in the areas with rugged terrain that provided protections form raids (Dimico, 2014). The rugged terrain is a "mixed blessing" since it also hinders economic development (Nunn and Puga, 2012), and low-development areas were prone to have more HIV/AIDS cases (Whiteside, 2002). Thus, a correlation between distance to missions and anti-gay sentiments could be spurious if this potential explanation is not adjusted for. In Table 1, we control for terrain ruggedness thus taking into account this explanation. In addition, in Table C.13, we add controls for individual socio-economic status, and in Columns II and III of Table C.14, we add controls for proxies for contemporary economic development (luminosity from satellite images and population density). The main result does not change.

\footnotetext{
${ }^{36}$ We control for cocoa and palm suitability in Column I of Table C.12. We don't have data on suitability of rubber and kola nuts. Rubber is mostly prevalent in Democratic Republic of Congo, and Afrobarometer has never conducted surveys there. Kola nuts are also very clustered in a small set of countries: Liberia, Niger, Nigeria, and Sierra Leone. Thus, we omit these countries in Column II of Table C.12 to show that results are not driven by kola nuts.
} 
Scenario 2: Slave Trade and Polygyny Missions were also more likely to appear near the coast. Distance to coast influenced the prevalence of slave trade, and legacies of the slave trade influenced modern outcomes (Nunn, 2008; Nunn and Wantchekon, 2011). One of the outcomes that are relevant for HIV / AIDS is the practice of polygyny (one man having several wives). Bertocchi and Dimico (2019) demonstrated that this practice was more likely to emerge in the areas that suffered demographic shock due to the slave trade. In Column V of Table C.4 we control for distance to coast and historical distance to coast is absorbed by ethnic homelands fixed effects in Column VI; our results still hold. Additionally, in Columns VI-VII of Table C.14, we split the sample into highpolygyny groups and low-polygyny groups and find that the main coefficient is the same for both groups. $^{37}$

Other Scenarios It is certainly possible that those two scenarios do not exhaust the possibility of potentially unobserved determinants of missionary activity also influencing the HIV / AIDS prevalence, and HIV / AIDS prevalence influencing the anti-gay sentiments. However, all those scenarios involve HIV / AIDS prevalence being on a back-door path between missionary activity and antigay sentiments. In Columns IV-V of Table C.14 we show that our results hold in countries that had a high prevalence of HIV / AIDS as well as countries with a low-level of HIV / AIDS (though the point estimates are higher for countries with high HIV / AIDS).

Table C.15 shows that distance to historical mission does not affect alternative outcomes, such as intolerance toward people of different religions in Column I, people of different ethnicities in Column II, people with HIV/AIDS in Column III, or immigrants and foreign workers in Column IV.

In case missions affected attitudes only in British colonies (because homosexuality was prohibited in the United Kingdom) in Table C.16 we show that our results hold separately on the subsamples of countries with and without British colonial presence (Columns I and II). We also don't find differential effects in Column III.

Counterfactual missions Finally, in the vein of Dell and Olken (2020) we conduct the following placebo test: we create 500 maps of randomly generated missions, conditional on parameters important for their location (Jedwab, zu Selhausen and Moradi 2019); i.e., we generate the same number of missions as we have in our 33 countries 500 times and compute minimum distance-tocounterfactual missions for each respondent in our data. ${ }^{38}$ Figure C.5 compares our true pointestimate to the distribution of point-estimates obtained using minimum distances with counterfactual missions. The true coefficient has by far the largest magnitude. This permutation test shows that the distance to the missions is of specific importance for current anti-gay sentiments as

\footnotetext{
${ }^{37}$ We computed country-level shares of polygamous households and HIV rates using data from the Demographic and Health Survey: https://dhsprogram.com/data/.

${ }^{38}$ First, we estimate the probability of having a mission in a grid cell using geographic controls (latitude and longitude, ruggedness, elevation, and distance-to-coast). Then, we estimate the propensity score and randomly place missions in cells among the top $15 \%$ of the cells that are the most similar to the cells with the actual missions.
} 
compared to other locations that have the same geographical features as the missions but lack the missions themselves.

\subsection{Potential Spuriousness Because of Spatial Autocorrelation}

Kelly (2020) shows that in the studies of the persistence of outcomes if the explanatory variable and the outcome both exhibit a high degree of spatial autocorrelation then the p-value for the statistical tests might be biased downwards, and thus lead to spurious conclusions. This issue might not be remedied by traditional methods such as Conley's standard errors that we report in Tables C.5 and C.3. We follow the approach recommended by Kelly (2020) and also report HAC standard errors with Matern kernel, where the appropriate range is selected using grid search The results are reported in Table C.20 in Appendix. As expected, the standard errors do widen somewhat, but our results remain significant on the 5 percent level. Thus, given that we use conventional significance reporting thresholds, our results are unlikely to be spurious because of spatial autocorrelation.

\section{Religious Conversion by Missions is the Most Plausible Mechanism}

In the previous section, we find that proximity to Christian missions is strongly associated with current anti-gay sentiments and argue that this association is indicative of the causal effect. Our interpretation of these results is that the missions influenced the religious conversion of the local indigenous population and the religious norms. In this Section, we provide suggestive evidence, that the spread of Christianity is the most likely channel through which historical missions affect contemporary attitudes toward homosexuals. ${ }^{39}$

To substantiate the aforementioned conclusion we perform several additional pieces of analysis. First, in Table 4 we perform the same regressions as in Table 1 using only nonreligious individuals (Column II). We do not find a statistically significant relationship between distance to the missions and anti-gay sentiments (if so, the coefficient even changes its sign). In Column III we also find no effect of missions on the subsample of respondents following traditional beliefs. In Column IV we estimate equation 1 on the subsample of Muslim respondents. While Islam also prohibits homosexual behaviour, if the effect of missions works through the spread of Christianity, we expect no effect on Muslim respondents. The resulting estimate is, indeed, very close to zero and insignificant. The coefficient remains insignificant when we combine all non-Christian respondents in Column V. Finally, in Column VI we include only respondents following any Christian denomination. The estimate is close to our baseline estimate and is highly significant. These results are consistent with the missions influencing current anti-gay attitudes through the mechanism of religious attainment.

Secondly, missions have been demonstrated to improve literacy (Carpenter, 1960; Dimico, 2014) and change political beliefs (Woodberry, 2012). Those things might have an impact on anti-gay

\footnotetext{
${ }^{39}$ We also confirm findings of Nunn (2010) by demonstrating that historical missions spread Christianity in Table C.19.
} 
sentiments that are not mediated by religion. In Table C.13, we control for those outcomes: educational attainment, urbanization, belief that democracy is the best form of government. Technically, those are "post-treatment" controls that are to be avoided if we are interested in the effects of missions, but we include them here to show that the non-religion channels do not explain away the effect of missions on anti-gay sentiments. Our results are robust to the inclusion of grid-level light intensity, population density, household assets, public goods dummies (access to electricity, type of toilet, and access to water), employment status, education dummies, and pro-democracy beliefs.

It is also worth pointing out that all the potential alternative channels have been shown to improve tolerance. ${ }^{40}$ In our estimations, we find the negative overall effects of missions on intolerance, so the alternative channels are likely to attenuate our estimates. ${ }^{41}$

Table 4: The effect of missions goes through Christians respondents only

\begin{tabular}{lcccccc}
\hline \hline & \multicolumn{1}{c}{ I } & II & III & IV & V & VI \\
\cline { 2 - 7 } & \multicolumn{7}{c}{ Sample } & \begin{tabular}{c} 
Dependent variable: Dislike homosexuals \\
Baseline \\
\cline { 2 - 7 }
\end{tabular} & No religion & $\begin{array}{c}\text { Traditional } \\
\text { beliefs }\end{array}$ & Muslim & $\begin{array}{c}\text { Non- } \\
\text { Christian }\end{array}$ & Christian \\
\cline { 2 - 7 } Min. distance-to-mission, 100km & $-0.0132^{* * *}$ & 0.014 & -0.031 & -0.003 & -0.001 & $-0.013^{* * *}$ \\
& $(0.0038)$ & $(0.0156)$ & $(0.0302)$ & $(0.0047)$ & $(0.0045)$ & $(0.0046)$ \\
R-squared & 0.282 & 0.393 & 0.282 & 0.223 & 0.304 & 0.273 \\
Observations & 50,337 & 1,675 & 796 & 13,197 & 17,590 & 32,671 \\
\hline
\end{tabular}

Note: (a) In all columns, we take the most demanding specification from the baseline results, i.e., Column V in Panel A of Table 1. (b) In Column II, we estimate the specification for the subsample of respondents that consider themselves not religious. (c) In Column III, we estimate the specification for the subsample of respondents whose religion is "traditional beliefs." (d) In Column IV, we estimate the specification for the subsample of respondents whose religion is any denomination of Islam. (e) In Column V, we estimate the specification for the subsample of respondents that are non-religious or whose religion is not a Christianity. (f) In Column V, we estimate the specification for the subsample of respondents whose religion is any denomination of Christianity. $(g)$ In parentheses we report standard errors clustered on the geographical unit level (village/town). ${ }^{* * *} \mathrm{p}<0.01,{ }^{* *} \mathrm{p}<0.05,{ }^{*} \mathrm{p}<0.1$

In Table C.17 we provide an additional test for whether the potential "modernizing" effect of missions can render our main results spurious: a separate estimation of the coefficients on the distance to the nearest mission for urban and rural respondents. Column I reports our baseline estimate (taken from Column V of Table 1) where we only control for urban fixed effects. In Column II, we replace $\beta \cdot$ Distance $_{v}$ with $\beta^{U} \cdot$ Distance $_{v} \cdot 1(\mathrm{Urban})_{i}$ and $\beta^{R} \cdot$ Distance $_{v} \cdot 1(\text { Rural })_{i}$. Thus, we test if the effect of proximity to the historical mission is significantly different from zero separately for rural and urban respondents. Both coefficients appear to be negative and statistically significant. In Column III we estimate the same specification, but with two separate sets of ethnicity fixed effects that are specific to respondent's urban/rural status, so that this specification mirrors

\footnotetext{
${ }^{40}$ Both urbanization and education are associated with lower-level of out-group biases. Specifically, Berge et al. (2020) report no significant co-ethnic bias among residents of Nairobi, Kenya, except for those who lived in Nairobi for less than ten years. Economic modernization, in general, is associated with more inclusive values (Inglehart and Welzel 2005).

${ }^{41}$ Another explanation, unrelated to religion, might be that missions helped spread conservative values that were not necessarily related to any religious doctrine. In an attempt to test this explanation with Afrobarometer, we regress the acceptance of female leaders on the distance to the missions and find no discernible effect (Table C.18).
} 
a split-sample estimation strategy in which the core estimation (1) would be run separately for rural and urban respondents, but at the same time imposes a common set of coefficients on other controls unrelated to urban status. While the significance of the $\beta^{R}$ is lower, both coefficients are significant and negative. The coefficients do not statistically differ from each other, with a p-value of 0.16 .

Another plausible mechanism is modern religious conversion. As demonstrated by Grossman (2015), U.S. Evangelical religious organizations ("megachurches") had a profound presence in Africa. If their presence was influenced by the same geographical characteristics that influenced the locations of colonial Christian missions, then the effect estimated in Table 1 would be spurious, To alleviate this concern, we perform two exercises in Table 5. First, Column II excludes Evangelical protestants (only $3.0 \%$ of our total sample or $4.9 \%$ of Christian sample) from our sample to demonstrate that the effect is not driven by the Evangelicals. This test, however, might be prone to error since people often change denominations, and because of the sheer amount of churches, not everyone who is associated with them might call themselves an "evangelical."

Table 5: Missions and anti-gay sentiments: heterogeneous effects by denomination

\begin{tabular}{|c|c|c|c|c|c|c|c|c|}
\hline & 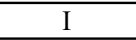 & II & III & IV & $\mathrm{V}$ & VI & VII & VIII \\
\hline \multicolumn{9}{|c|}{ Dependent variable: Dislike homosexuals } \\
\hline Sample & Christian & $\begin{array}{c}\text { No } \\
\text { Evalengelical }\end{array}$ & Only Catholic & $\begin{array}{l}\text { Only non- } \\
\text { Catholic }\end{array}$ & & & & All \\
\hline $\begin{array}{r}\text { Min. distance-to-mission, } \\
100 \mathrm{~km}\end{array}$ & $\begin{array}{c}-0.013 * * * \\
(0.0046)\end{array}$ & $\begin{array}{l}-0.012^{* *} \\
(0.0046)\end{array}$ & $\begin{array}{l}-0.012^{*} \\
(0.0068)\end{array}$ & $\begin{array}{l}-0.013^{* *} \\
(0.0064)\end{array}$ & & & & \\
\hline $\begin{array}{l}\text { Min. distance to Catholic } \\
\text { mission, } 100 \mathrm{~km}\end{array}$ & & & & & $\begin{array}{c}-0.008 * * * \\
(0.0028)\end{array}$ & & $\begin{array}{c}-0.006 * * \\
(0.0024)\end{array}$ & \\
\hline $\begin{array}{l}\text { Min. distance to Protestant } \\
\text { mission, } 100 \mathrm{~km}\end{array}$ & & & & & & $\begin{array}{c}-0.012 * * * \\
(0.0043)\end{array}$ & & $\begin{array}{r}-0.007 * * \\
(0.0030)\end{array}$ \\
\hline R-squared & 0.273 & 0.278 & 0.297 & 0.273 & 0.273 & 0.273 & 0.281 & 0.281 \\
\hline Observations & 32,671 & 31,063 & 10,504 & 22,110 & 32,671 & 32,671 & 50,329 & 50,329 \\
\hline
\end{tabular}

Note: (a) In all columns, we take the most demanding specification from the baseline results, i.e., Column $\mathrm{V}$ in Panel $\mathrm{A}$ of Table 1. (b) Column I replicates Column VI of Table 4; i.e., we estimate the specification for the subsample of respondents whose religion is any denomination of Christianity. (c) In Column II, we estimate the specification for the subsample of Christian respondents that do not identify themselves as Evangelical. (d) In Column III, we estimate the specification for the subsample of Catholic respondents. (e) In Column IV, we estimate the specification for the subsample of non-Catholic respondents. (f) Columns V-VIII report on specification (1) but replaces minimum distance to any mission $\left(\beta \cdot\right.$ Distance $\left._{v}\right)$ with $\beta^{C} \cdot$ min distance to Catholic mission and $\beta^{C}$. min. distance to Protestant mission $_{v}$. $(g)$ In Columns V-VI, we estimate the specification for the subsample of respondents whose religion is any denomination of Christianity. (h) In parentheses we report standard errors clustered on the geographical unit level (village/town). ${ }^{* * *} \mathrm{p}<0.01,{ }^{* *} \mathrm{p}<0.05,{ }^{*} \mathrm{p}<0.1$

To alleviate this issue, we also perform a stronger test by excluding all non-Catholic denominations in Column III. Since conversion to Catholicism is unlikely to result from the activities of U.S. Evangelical Churches, the statistically significant effect we get once non-Catholics are excluded might alleviate the concerns. Column IV reports coefficient for the subsample of non-Catholic Christian respondents. These results suggest no difference on the effects on Catholic and nonCatholic population. Finally, Columns V-VIII also check whether Catholic and Protestant historical missions had differential effects on anti-gay sentiments. We find approximately similar effects 
for Catholic and Protestant missions. ${ }^{42}$

Overall, while the Christian missions certainly influenced not only religion but an array of other outcomes (literacy, political beliefs, etc.), when it comes to anti-gay sentiments as an outcome, religious conversion is the most plausible mechanism.

\section{Discussion and Conclusion}

In this paper, we argue that religious conversion by Christian missions in Africa caused antigay norms and that these attitudes later persisted. Using geo-coded Afrobarometer data, we demonstrate that negative attitudes towards homosexual persons are positively associated with a distance to colonial Christian mission sites. We explore the plausible violations of the identifying assumptions: geographical fundamentals determining both the locations of the missions and antigay attitudes, pre-colonial anti-gay attitudes being correlated with the locations of the missions, and others. We conclude that those alternative explanations do not seem to drive our results. We argue that the most plausible mechanism of the impact of Christian missions on anti-gay attitudes today is religious conversion since the effect only exists in the subsample of Christian respondents, and does not change once both individual-level and aggregate-level variables that also could be potentially influenced by missionary activity (literacy, poverty, etc.) are included in the regression.

Our study demonstrates how religious conversion can change norms and attitudes. The analysis is necessarily limited to one religion and one set of attitudes. However, we find it plausible that these results might be generalizable to other religions (specifically, the ones prescribing a tight moral code, like Islam and Judaism) and other norms and values.

We have also left out of the discussion the potential impact of norms and values on public policy. Appendix Section B presents correlations between the number of Christian missions and criminalization of homosexuality in African countries, but this evidence is only suggestive.

It is also not our contention that Christian activity is the only important determinant of anti-gay attitudes. It has been documented that the activity of U.S. megachurches (Grossman, 2015) and the abstinence-only response to the HIV epidemic (Anthony, 2018) also contributed to the intolerance. We leave quantitative exploration of interactions of these and other contemporary processes with missionary legacies to further research.

\footnotetext{
${ }^{42}$ While the difference between the effects of Catholic and Protestant missions is statistically insignificant, the pointestimate is slightly larger for the Protestant missions (Column VI). This is in line with Cagé and Rueda (forthcoming) who find that Catholic missions were less successful at converting, especially in former French colonies.
} 


\section{References}

Afrobarometer. 2016. Afrobarometer Round 6: The Quality of Democracy and Governance in 36 African Countries, 2016. available at http:/ / www.afrobarometer.org.

Alesina, Alberto, and Paola Giuliano. 2015. "Culture and institutions." Journal of Economic Literature, 53(4): 898-944.

Alesina, Alberto, Paola Giuliano, and Nathan Nunn. 2013. "On the origins of gender roles: Women and the plough." The Quarterly Journal of Economics, 128(2): 469-530.

Alesina, Alberto, Sebastian Hohmann, Stelios Michalopoulos, and Elias Papaioannou. 2019. “Intergenerational Mobility in Africa." National Bureau of Economic Research.

Algan, Yann, and Pierre Cahuc. 2010. “Inherited trust and growth." American Economic Review, 100(5): $2060-92$.

Amnesty International. 2013. "Making Love a Crime, Criminalization of Same-Sex Conduct in Sub-Saharan Africa."

Anderson, Ben. 2007. “The politics of homosexuality in Africa." Africana, 1(1): 123-136.

Anthony, Constance G. 2018. "Schizophrenic Neocolonialism: Exporting the American Culture War on Sexuality to Africa." International Studies Perspectives, 19(4): 289-304.

Atlas Narodov Mira. 1964. "Moscow: Miklukho-Maklai Ethnological Institute at the Department of Geodesy and Cartography of the State Geological Committee of the Soviet Union."

Awondo, Patrick, Peter Geschiere, and Graeme Reid. 2012. "Homophobic Africa? Toward a more nuanced view." African Studies Review, 145-168.

Baranov, Victoria, Ralph De Haas, and Pauline A Grosjean. 2018. “Men. Roots and Consequences of Masculinity Norms."

Barro, Robert J, and Rachel M McCleary. 2003. "Religion and economic growth across countries." American sociological review, 68(5): 760-781.

Becker, Sascha O, and Ludger Woessmann. 2018. "Social cohesion, religious beliefs, and the effect of Protestantism on suicide." Review of economics and statistics, 100(3): 377-391.

Bentzen, Jeanet Sinding, and Lena Lindbjerg Sperling. 2020. "God Politics: Religion, Attitudes, and Outcomes."

Berge, Lars Ivar Oppedal, Kjetil Bjorvatn, Simon Galle, Edward Miguel, Daniel N Posner, Bertil Tungodden, and Kelly Zhang. 2020. "Ethnically biased? Experimental evidence from Kenya." Journal of the European Economic Association, 18(1): 134-164.

Bergeron, Augustin. 2020. "Religion and the Scope of Cooperation: Evidence from Exposure to Missions in the DRC." Working Paper.

Bertocchi, Graziella, and Arcangelo Dimico. 2019. “The long-term determinants of female HIV infection in Africa: The slave trade, polygyny, and sexual behavior." Journal of Development Economics, 140: 90-105.

Binzel, Christine, and Jean-Paul Carvalho. 2017. "Education, social mobility and religious movements: The Islamic revival in Egypt." The Economic Journal, 127(607): 2553-2580.

Black, Dan, Gary Gates, Seth Sanders, and Lowell Taylor. 2002. “Why do gay men live in San Francisco?" Journal of Urban Economics, 51(1): 54-76.

Bosia, Michael J. 2014. "Strange fruit: Homophobia, the state, and the politics of LGBT rights and capabilities." Journal of Human Rights, 13(3): 256-273.

Brodeur, Abel, and Joanne Haddad. 2018. "Institutions, Attitudes and LGBT: Evidence from the Gold Rush."

Cagé, Julia, and Valeria Rueda. 2016. "The long-term effects of the printing press in Sub-Saharan Africa." American Economic Journal: Applied Economics, 8(3): 69-99.

Cagé, Julia, and Valeria Rueda. forthcoming. "Sex and the Mission: The conflicting effects of early Christian investments on HIV in sub-Saharan Africa." Journal of Demographic Economics.

Cameron, A Colin, Jonah B Gelbach, and Douglas L Miller. 2011. "Robust inference with multiway clustering." Journal of Business \& Economic Statistics, 29(2): 238-249.

Carpenter, George Wayland. 1960. “African education and the Christian missions.” The Phi Delta Kappan, 41(4): $191-195$.

Carroll, Aengus. 2016. State-Sponsored Homophobia: A World Survey of Sexual Orientation Laws-Criminalisation, Protection and Recognition. International Lesbian, Gay, Bisexual, Trans and Intersex Association. 
Carvalho, Jean-Paul. 2019. "Religious clubs: The strategic role of religious identity." In Advances in the Economics of Religion. 25-41. Springer.

Carvalho, Jean-Paul, and Mark Koyama. 2016. “Jewish emancipation and schism: Economic development and religious change." Journal of Comparative Economics, 44(3): 562-584.

Carvalho, Jean-Paul, Sriya Iyer, and Jared Rubin. 2019. Advances in the Economics of Religion. Springer.

Chaney, Eric. 2019. "Religion, political power and human capital formation: Evidence from islamic history." In Advances in the Economics of Religion. 437-448. Springer.

Cheney, Kristen. 2012. "Locating neocolonialism, "tradition," and human rights in Uganda's "Gay Death Penalty"." African Studies Review, 55(2): 77-95.

Conley, Timothy G. 2010. "Spatial econometrics." In Microeconometrics. 303-313. Springer.

Connor, Jonathan. 2011. “Development for whom? Homosexuality and faith-based development in Zimbabwe." Development in Practice, 21(6): 860-869.

Currier, Ashley. 2018. Politicizing Sex in Contemporary Africa: Homophobia in Malawi. Cambridge University Press.

Dell, Melissa, and Benjamin A Olken. 2020. "The development effects of the extractive colonial economy: the Dutch cultivation system in Java." The Review of Economic Studies, 87(1): 164-203.

De Rachewiltz, Boris. 1964. Black eros: sexual customs of Africa from prehistory to the present day. L. Stuart.

Dimico, Arcangelo. 2014. "Poverty trap and educational shock: Evidence from missionary fields." QUCEH Working Paper Series.

Epprecht, Marc. 2006. "“" Bisexuality" and the politics of normal in African Ethnography." Anthropologica, 187-201.

Epprecht, Marc. 2008. "Unspoken facts: A history of homosexualities in Africa."

Gaudio, Rudolf P. 1998. âMale Lesbians E Other Queer Notions in Hausâa, from S. Murray E W. Roscoe (eds) Boy Wives E Female Husbands: Studies of African Homosexualities. na.

Gershman, Boris. 2015. "The economic origins of the evil eye belief." Journal of Economic Behavior E Organization, 110: 119-144.

Grosjean, Pauline, and Rose Khattar. 2019. "It's raining men! Hallelujah? The long-run consequences of male-biased sex ratios." The Review of Economic Studies, 86(2): 723-754.

Grossman, Guy. 2015. "Renewalist Christianity and the political saliency of LGBTs: Theory and evidence from SubSaharan Africa." The Journal of Politics, 77(2): 337-351.

Herdt, Gilbert. 1991. "Representations of homosexuality: An essay on cultural ontology and historical comparison part i." Journal of the History of Sexuality, 1(3): 481-504.

Herek, Gregory M, and John P Capitanio. 1999. "AIDS stigma and sexual prejudice." American behavioral scientist, 42(7): 1130-1147.

Inglehart, Ronald, and Christian Welzel. 2005. Modernization, cultural change, and democracy: The human development sequence. Cambridge University Press.

Jedwab, Remi, Felix Meier zu Selhausen, and Alexander Moradi. 2019. "The Economics of Missionary Expansion: Evidence from Africa and Implications for Development." Centre for the Study of African Economies, University of Oxford CSAE Working Paper Series 2018-07.

Kaoma, Kapya. 2018. Christianity, globalization, and protective homophobia. Springer.

Kelly, Morgan. 2020. “Understanding Persistence."

Kendall, K Limakatso. 1998. “'When a Woman Loves a Woman': In Lesotho: Love, Sex, and the (Western) Construction of Homophobia."

Klinken, Adriaan van. 2014. "Homosexuality, politics and Pentecostal nationalism in Zambia." Studies in World Christianity, 20(3): 259-281.

Kudo, Yuya. 2017. "Missionary influence on marriage practices: Evidence from the Livingstonia Mission in Malawi." Journal of African Economies, 26(3): 372-431.

Lyonga, Frida. 2016. "Pentecostal endtime, prosperity and healing gospels as contributors to homophobia in Cameroon." Christianity and controversies over homosexuality in contemporary Africa.

Maxwell, David. 2000. “Post-colonial Christianity in Africa.” World Christianities c. 1914-c, 401-422. 
M'Baye, Babacar. 2013. "The origins of Senegalese homophobia: Discourses on homosexuals and transgender people in colonial and postcolonial Senegal." African Studies Review, 109-128.

Michalopoulos, Stelios, and Elias Papaioannou. 2013. "National institutions and subnational development in Africa." The Quarterly journal of economics, 129(1): 151-213.

Mokyr, Joel. 2016. A culture of growth: the origins of the modern economy. Princeton University Press.

Murdock, George P. 1967. "Ethnographic Atlas. Pittsburgh."

Murray, Stephen O, and Will Roscoe. 1998. Boy-wives and female-husbands: Studies in African homosexualities.

Narrain, Arvind, Adrian Jjuuko, Monica Tabengwa, Gary Kinsman, Amar Wahab, Pere DeRoy, Namela Baynes Henry, Monica Mbaru, Kim Vance, Nick J Mulé, et al. 2018. Envisioning global LGBT human rights:(neo) colonialism, neoliberalism, resistance and hope. Human Rights Consortium, School of Advanced Study, University of London.

Nunn, Nathan. 2008. "The long-term effects of Africa's slave trades." The Quarterly Journal of Economics, 123(1): 139-176.

Nunn, Nathan. 2010. "Religious conversion in colonial Africa." American Economic Review: Papers and Proceedings, 100(2): 147-52.

Nunn, Nathan, and Diego Puga. 2012. “Ruggedness: The blessing of bad geography in Africa." Review of Economics and Statistics, 94(1): 20-36.

Nunn, Nathan, and Leonard Wantchekon. 2011. "The slave trade and the origins of mistrust in Africa." American Economic Review, 101(7): 3221-52.

Nunn, Nathan, Emmanuel Akyeampong, Robert Bates, and James A Robinson. 2014. “Gender and missionary influence in colonial Africa." African development in historical perspective.

Nwoko, Kenneth Chukwuemeka. 2012. "Female Husbands in Igbo Land: Southeast Nigeria." The Journal of Pan African Studies, 5(1): 69-82.

Oguntola-Laguda, Danoye, and Adriaan van Klinken. 2016. "Uniting a Divided Nation? Nigerian Muslim and Christian Responses to the Same-Sex Marriage (Prohibition) Act." In Public Religion and the Politics of Homosexuality in Africa. 35-48. Routledge.

Pelikan, Jaroslav. 1958. Luther's works. Concordia Publishing House.

Robinson, David. 2004. Muslim societies in African history. Vol. 2, Cambridge University Press.

Rubin, Jared. 2017. Rulers, Religion, and Riches: Why the West got rich and the Middle East did not. Cambridge University Press.

Thoreson, Ryan Richard. 2014. "Troubling the waters of a âwave of homophobiaâ: Political economies of anti-queer animus in sub-Saharan Africa." Sexualities, 17(1-2): 23-42.

Tomes, Nigel. 1984. "The effects of religion and denomination on earnings and the returns to human capital." Journal of Human Resources, 472-488.

Valencia Caicedo, Felipe. 2019. "The mission: Human capital transmission, economic persistence, and culture in South America." The Quarterly Journal of Economics, 134(1): 507-556.

Valois, Caroline. 2016. "Scandal makers: Competition in the religious market among Pentecostal-Charismatic churches in Uganda." In Christianity and Controversies over Homosexuality in Contemporary Africa. 48-60. Routledge.

Van Hoorn, André, and Robbert Maseland. 2013. “Does a Protestant work ethic exist? Evidence from the well-being effect of unemployment." Journal of Economic Behavior E Organization, 91: 1-12.

Whiteside, Alan. 2002. "Poverty and HIV / AIDS in Africa." Third world quarterly, 23(2): 313-332.

Woodberry, Robert D. 2012. "The missionary roots of liberal democracy." American Political Science Review, 106(2): 244274.

Zak, Paul J, and Stephen Knack. 2001. "Trust and growth." The economic journal, 111(470): 295-321.

Zandt, Maria. 2011. "The situation of Christians in Sub-Saharan Africa." KAS International Reports, 6: 32-51. 


\section{Online Appendix}

to

"Christian Missions and Anti-Gay Attitudes in Africa: 


\section{A Intolerance Today is Highly Correlated with Religiosity}

In this section, we present descriptive evidence consistent with current intolerance to homosexuals being largely explained by current religiosity. We start by showing correlations of selfreported intolerance toward gay persons and demographic and socio-economic controls from the Afrobarometer survey. We estimate the following OLS regression on individual-level data:

$$
\text { Intolerance }_{i(c)}=\alpha_{c}+\beta^{R} \cdot \text { Religion }_{i(c)}+X_{i(c)} \Gamma+\varepsilon_{i(c)},
$$

where Intolerance ${ }_{i}$ is a dummy equal to one if a respondent $i$ nested within country $c$ strongly dislikes having homosexual neighbors and 0 otherwise; Religion $i$ is a matrix of dummies for the religion denominations; $X_{i(c)}$ is a matrix of individual-level controls; and $\alpha_{c}$ is a set of country fixed effects.

There is compelling evidence of the positive correlation between anti-gay sentiments and Religion (Christianity and Islam) in Africa (e.g., Grossman 2015). Table A.1 presents the results. We find evidence that is suggestive of respondents following Abrahamic religion denominations more likely to be intolerant toward gay persons, and that confirms existing results: the coefficient on a respondent being Christian or Muslim is positive relative to the "no religion" baseline. However, we do not find a significant coefficient for the respondents' following traditional religious beliefs, also consistent with the aforementioned anthropological literature.

Being Muslim is associated with higher intolerance throughout all columns. The coefficient for Christians is also always significant but smaller in magnitude. On average, our estimations show that Christian respondents are 9.4 percentage points more likely to reveal anti-gay attitudes in the survey. The coefficients for Muslim respondents appear to be the largest: being Muslim corresponds to 12.6 percentage points larger probability of disliking having homosexual neighbors conditional on the full set of controls and fixed effects.

Also, we find that the urban population is less likely to report an anti-gay attitude. While income and education are often associated with more inclusive values (Inglehart and Welzel 2005) we do not find any significant correlation between intolerance toward gay persons and these factors.

Overall, aside from the urban status, religion is the only robust non-demographic variable that is consistently positively correlated with the intolerance across various specifications. Consistently with the anthropological literature, only the coefficient for respondents practicing traditional ethnic beliefs exhibits no signs of correlation with the anti-gay sentiments. 
Table A.1: Contemporary correlates of intolerance

\begin{tabular}{|c|c|c|c|c|c|c|}
\hline & I & II & III & IV & V & VI \\
\hline & \multicolumn{6}{|c|}{ Dependent variable: Dislike homosexuals } \\
\hline Christian & $\begin{array}{c}0.128 * * * \\
(0.015)\end{array}$ & $\begin{array}{c}0.142 * * * \\
(0.017)\end{array}$ & $\begin{array}{c}0.143 * * * \\
(0.016)\end{array}$ & $\begin{array}{c}0.142 * * * \\
(0.015)\end{array}$ & $\begin{array}{c}0.089 * * * \\
(0.011)\end{array}$ & $\begin{array}{c}0.094 * * * \\
(0.011)\end{array}$ \\
\hline Muslim & $\begin{array}{c}0.149 * * * \\
(0.034)\end{array}$ & $\begin{array}{c}0.156^{* * *} \\
(0.034)\end{array}$ & $\begin{array}{c}0.160 * * * \\
(0.034)\end{array}$ & $\begin{array}{c}0.161 * * * \\
(0.035)\end{array}$ & $\begin{array}{c}0.139 * * * \\
(0.040)\end{array}$ & $\begin{array}{c}0.126 * * * \\
(0.039)\end{array}$ \\
\hline Traditional & $\begin{array}{r}-0.006 \\
(0.021)\end{array}$ & $\begin{array}{l}-0.010 \\
(0.021)\end{array}$ & $\begin{array}{l}-0.011 \\
(0.020)\end{array}$ & $\begin{array}{r}-0.011 \\
(0.020)\end{array}$ & $\begin{array}{l}0.002 \\
(0.014)\end{array}$ & $\begin{array}{l}0.001 \\
(0.015)\end{array}$ \\
\hline Urban & & $\begin{array}{c}-0.033 * * * \\
(0.011)\end{array}$ & $\begin{array}{c}-0.029 * * \\
(0.011)\end{array}$ & $\begin{array}{c}-0.022 * * \\
(0.011)\end{array}$ & $\begin{array}{c}-0.022 * * \\
(0.008)\end{array}$ & $\begin{array}{c}-0.023 * * * \\
(0.008)\end{array}$ \\
\hline Household wealth & & & $\begin{array}{c}-0.003 \\
(0.003)\end{array}$ & $\begin{array}{r}-0.000 \\
(0.002)\end{array}$ & $\begin{array}{l}-0.002 \\
(0.002)\end{array}$ & $\begin{array}{r}-0.002 \\
(0.002)\end{array}$ \\
\hline Employed & & & $\begin{array}{l}-0.009 \\
(0.009)\end{array}$ & $\begin{array}{l}-0.005 \\
(0.009)\end{array}$ & $\begin{array}{l}-0.008 \\
(0.008)\end{array}$ & $\begin{array}{l}-0.006 \\
(0.008)\end{array}$ \\
\hline Secondary education & & & & $\begin{array}{r}-0.010 \\
(0.008)\end{array}$ & $\begin{array}{l}-0.004 \\
(0.009)\end{array}$ & $\begin{array}{l}-0.002 \\
(0.009)\end{array}$ \\
\hline Demographic controls & $\checkmark$ & $\checkmark$ & $\checkmark$ & $\checkmark$ & $\checkmark$ & $\checkmark$ \\
\hline Country FEs & $\checkmark$ & $\checkmark$ & $\checkmark$ & $\checkmark$ & & \\
\hline Region FEs & & & & & $\checkmark$ & $\checkmark$ \\
\hline Ethnicity FEs & & & & & & $\checkmark$ \\
\hline R-squared & 0.263 & 0.264 & 0.264 & 0.266 & 0.310 & 0.320 \\
\hline Observations & 50,321 & 50,321 & 50,321 & 50,321 & 50,321 & 50,321 \\
\hline
\end{tabular}

Note: (a) The estimates for the effects of different religions on intolerance toward gay persons is relative to the respondents with no religion or of other religious denominations. $(b)$ All regressions include constant. Demographic controls include gender, age, and age squared. Household wealth is the first principle component of four asset-ownership dummies (car/motorcycle, radio, TV, and mobile phone). (c) Regions are nested within countries and country fixed effects are absorbed by region fixed effects in Columns V and VI. (d) In parentheses we report standard errors clustered on the country level. 33 clusters. ${ }^{* * *} \mathrm{p}<0.01,{ }^{* *} \mathrm{p}<0.05,{ }^{*} \mathrm{p}<0.1$ 


\section{B Presence of Historical Missions and Contemporary Anti-Gay Legislation}

African anti-gay legislation is correlated with the number of historical missions. To show that historical missions in a country correlate with the country's same-sex-related legislation we estimate the following regression:

$$
\text { AntiGayLaws }_{c}=\alpha+\beta \cdot \ln \left(\# \text { missions }_{c}\right)+\varepsilon_{c},
$$

where AntiGayLaws is a dependent variable that is equal to (i) a dummy equal to one if a country $c$ allows homosexual behavior, and zero otherwise; (ii) variable that is equal to one if a country has criminal punishment for homosexuality, equal to two if it imposes the death sentence for a samesex relationship, and equal to zero if there is no criminal punishment. We coded same-sex related legislation from Amnesty International (2013). The explanatory variable is the log of the total number of missions summed within post-colonial country borders.

Table B.1 reports how the total number of historical missions in a country correlates with the country's same-sex-related legislation. Column I demonstrates that it negatively correlates with the indicator variable for having laws allowing the same-sex activity. Column II shows that it positively correlates with a dummy for the same-sex activity to be punishable by law.

Table B.1: Missions and anti-gay legislation

\begin{tabular}{lcc}
\hline \hline & \multicolumn{1}{c}{ I } & II \\
\cline { 2 - 3 } & \multicolumn{2}{c}{ Dependent variable: } \\
\cline { 2 - 3 } & $\begin{array}{c}\text { Laws allowing } \\
\text { same-sex activity }\end{array}$ & Punished by law \\
\cline { 2 - 3 } Log missions & $-0.145^{* *}$ & $0.112^{* *}$ \\
& $(0.064)$ & $(0.049)$ \\
& 0.157 & 0.077 \\
R-squared & 36 & 53 \\
Observations & & \\
\hline \hline
\end{tabular}

Note: (a) All regressions include constant. (b) In parentheses we report robust standard errors ${ }^{* * *} \mathrm{p}<0.01,{ }^{* *} \mathrm{p}<0.05,{ }^{*} \mathrm{p}<0.1$ 


\section{Additional Results, Robustness, and Sensitivity Checks}

Figure C.1: Distribution of the respondents' answers regarding tolerance toward homosexuals

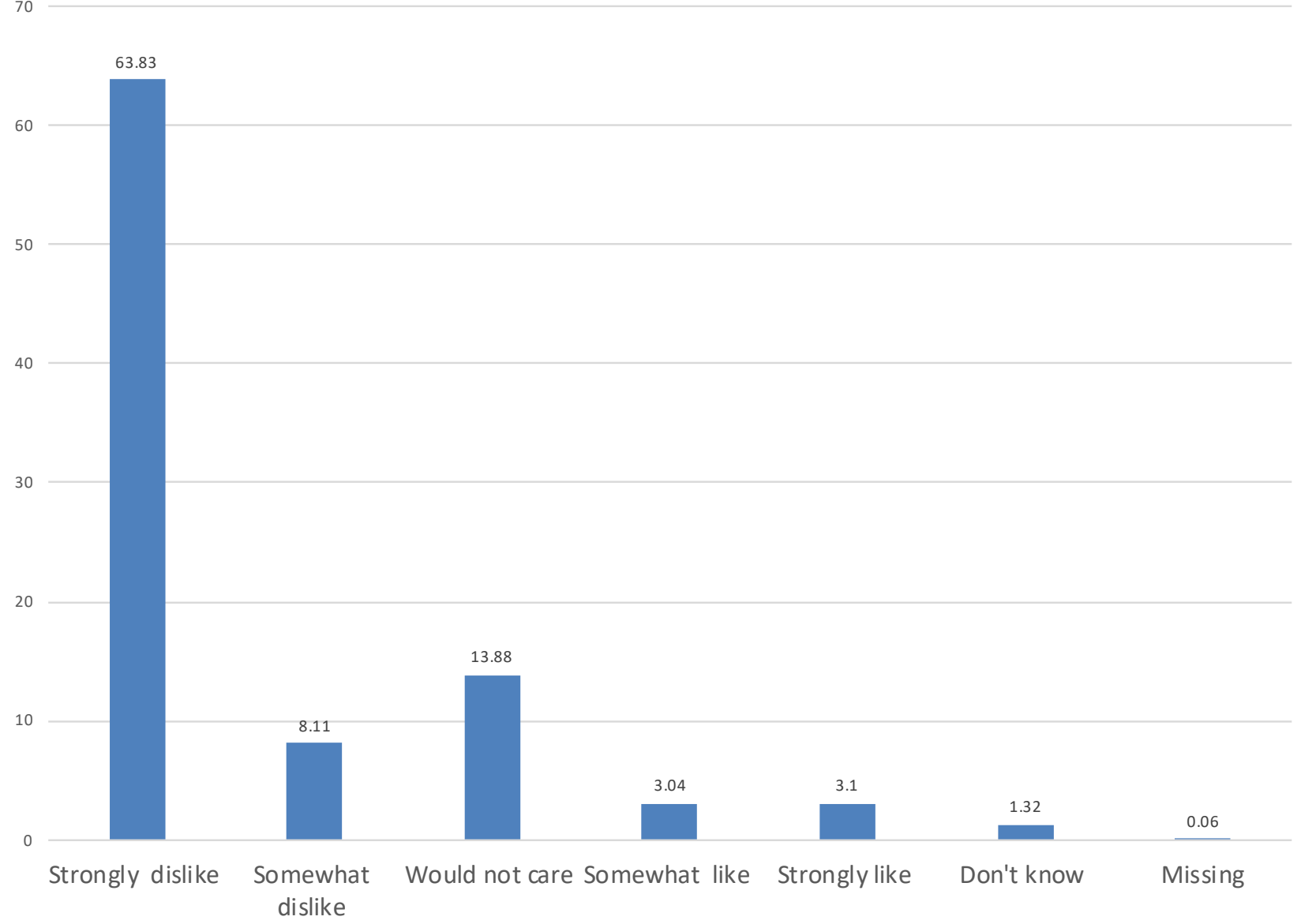

Source: Sixth wave of Afrobarometer. 
Figure C.2: Average level of intolerance toward homosexuals

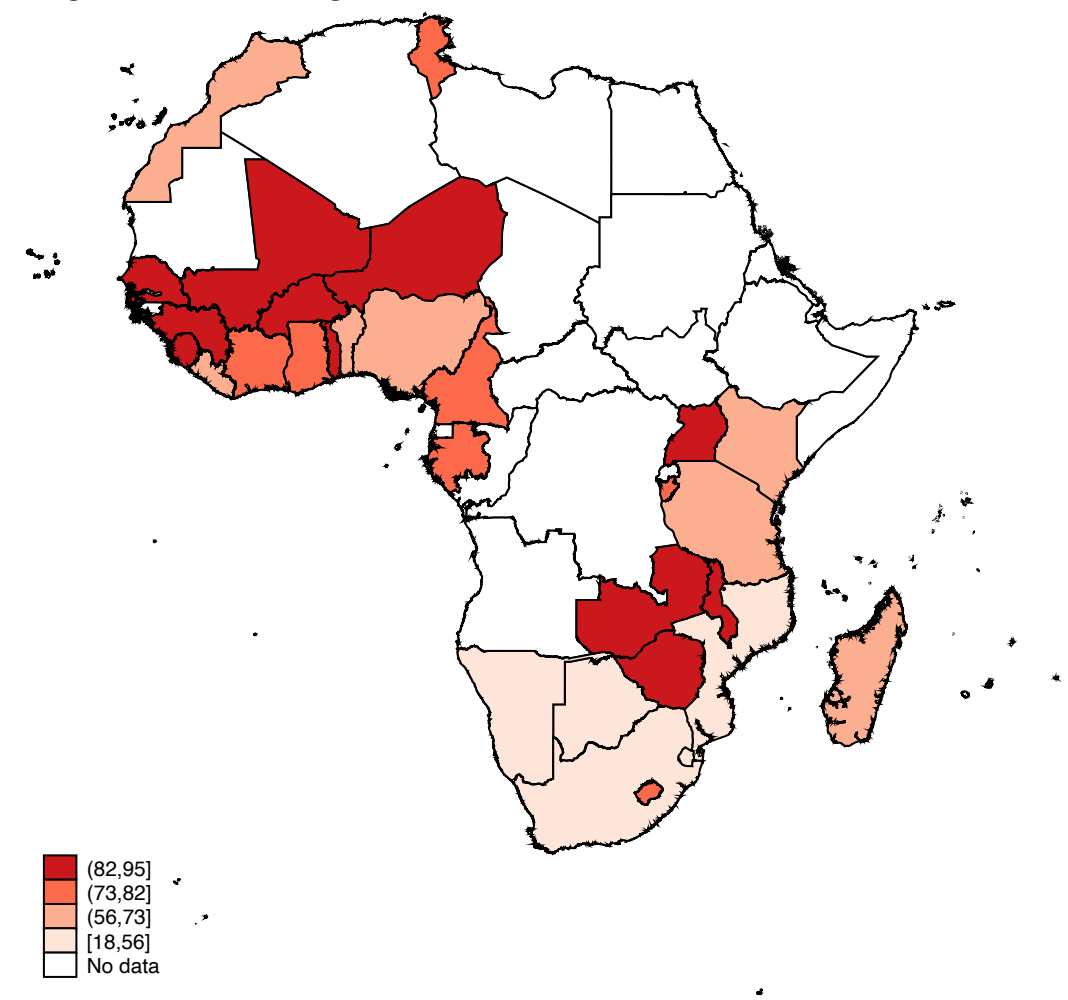

Source: Sixth wave of Afrobarometer. 
Figure C.3: Ethnic groups with pre-colonial same-sex patterns

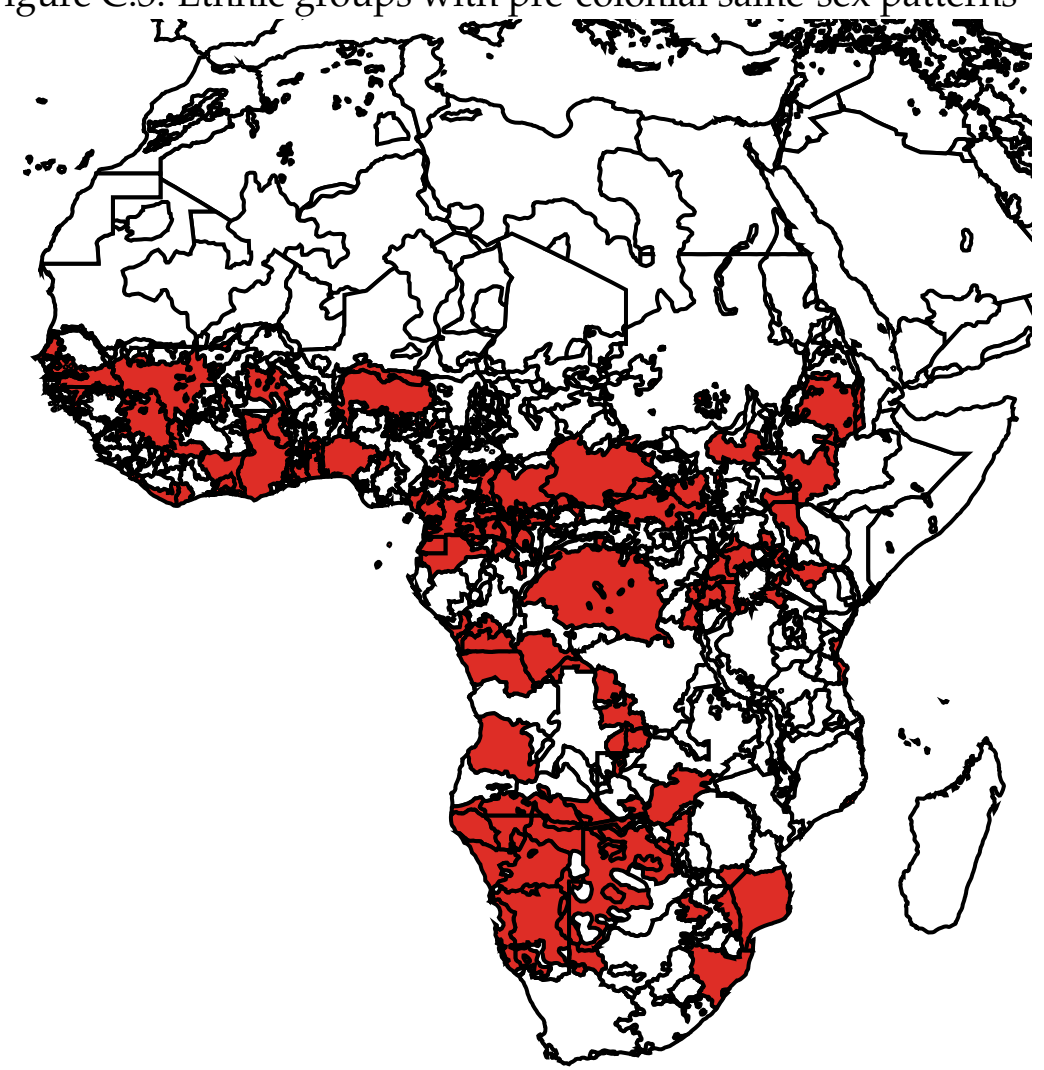

Source: Here we use ethnic group locations shapefile from Geo-referencing of ethnic groups (GREG, Atlas Narodov Mira, 1964). Precolonial same-sex patterns are from Murray and Roscoe (1998). 
Figure C.4: Robustness to an omission of a country

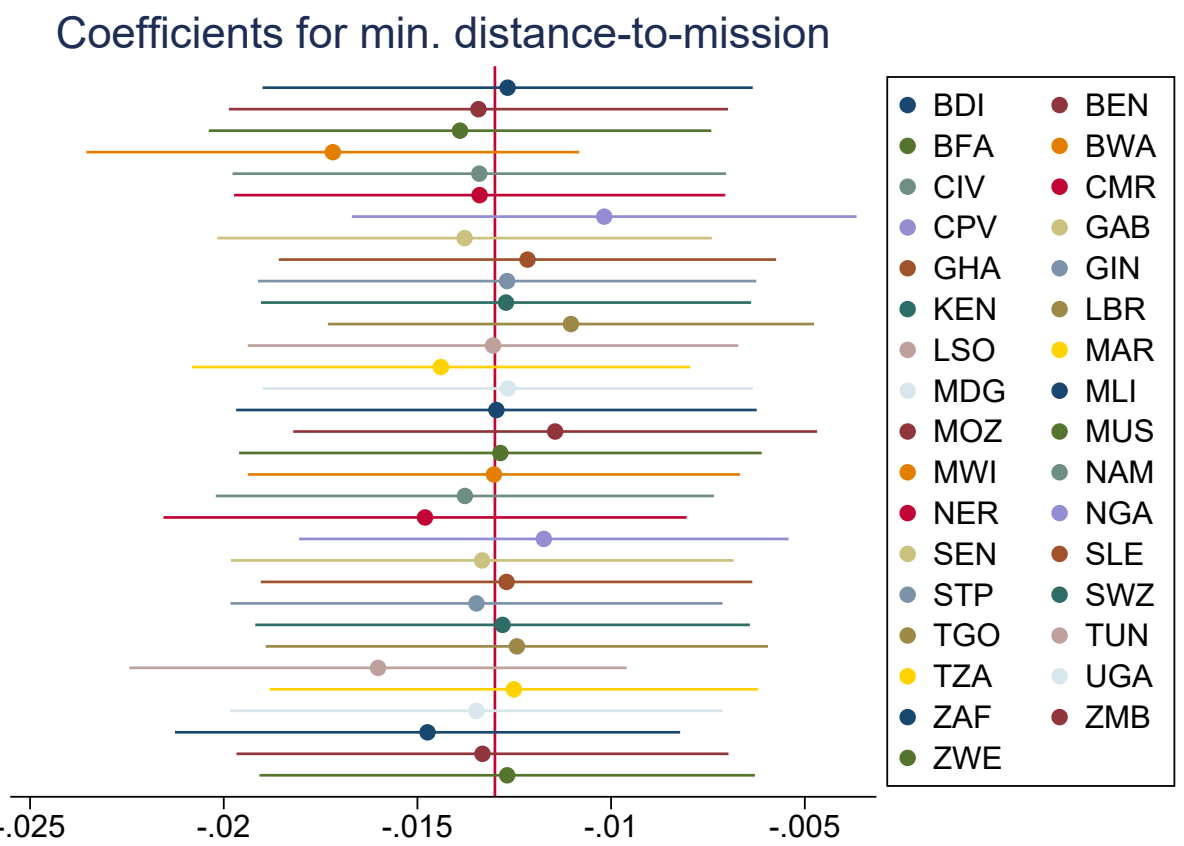

Note: (a) This figure reports on the results of estimating equation (1). The red vertical line is the point-estimate of $\widehat{\beta}$. We then report the point-estimates and confidence bands that result from re-estimating equation (1) but dropping one country at a time (in alphabetical order, omit Burundi (BDI), then Benin (BEN), and etc.), as indicated in the legend. 
Figure C.5: The effect of the counterfactual missions

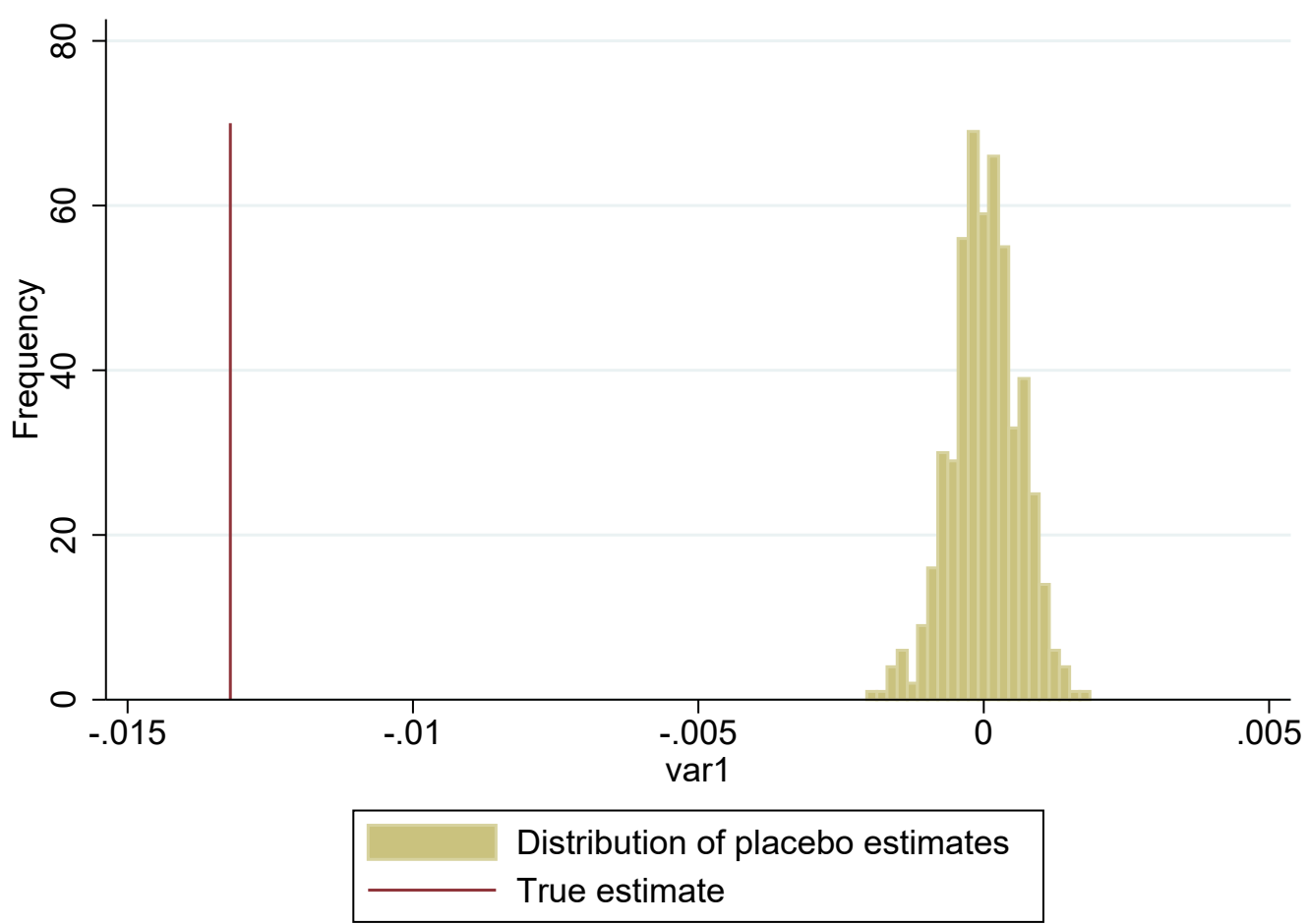

Note: (a) In this Figure, we take the most demanding specification from the baseline results, i.e., Column V in Panel A of Table 1. (b) This Figure shows estimated coefficients using 500 placebo locations for missions. All counterfactual estimates are smaller in magnitude then the true estimate. (c) The red vertical line is the true point-estimate of $\widehat{\beta}$. 
Table C.1: Crosswalk between the names of the ethnolinguistic groups in Murdock (1967) and Murray and Roscoe (1998)

\begin{tabular}{|c|c|}
\hline Ethnonym in Murray and Roscoe (1988) & Ethnonym in Murdock (1967) \\
\hline Akan (Ashame) & Akan \\
\hline Ambo/Ovambo (Wanyama) & Ambo \\
\hline Amhara (Amharic) & Amhara \\
\hline Anyi/Anyin & Akan \\
\hline Bafia (Fia) & Tikar \\
\hline Baganda & Baganda \\
\hline Bagishu/Bageshu, Gisu & Baluhya \\
\hline Bala/Basongye/Basonge/Songe & Banda \\
\hline Bambala/Mbala & Mbala \\
\hline Bamhara & $-*$ \\
\hline Bangala/Mbangala & Mbangala \\
\hline Dagaari/Dagara & Mandingo \\
\hline Dahomey (Fan) & Ewe \\
\hline Duala & Duala \\
\hline Eritrean (various) & Agau \\
\hline Fanti/Fante (Akan) & Akan \\
\hline Gangelia/Ovigangella & Bantu-speaking Pygmy tribes \\
\hline Gikuyu/Kikuyu & Akikuyu \\
\hline Gisa (Masaba) & Baluhya \\
\hline Hausa & Hausa \\
\hline Herero (Damara) & Herero \\
\hline Ila & Tonga \\
\hline Iteso/Teso & Teso \\
\hline Kongo & Bakongo \\
\hline Konso & Sidamo \\
\hline Krongo/Korongo/Kurungo & Kadugli-Krongo \\
\hline Kru & Lagoon tribes \\
\hline Lango & Lango \\
\hline Maale/Male/Maalia & Maale \\
\hline Maragoli/Logooli & Baluhya \\
\hline Meru & Akikuyu (Kikuyu) \\
\hline Mesakin (Ngile) & Ngile \\
\hline Mombasa (Swahili) & Swahili \\
\hline Mossi (More) & Mossi \\
\hline Mpondo/Pondo (Pana) & Ndebele \\
\hline Naman/Hottentot/Kaffir & Hottentots \\
\hline Nandi & Nandi \\
\hline Ndemu (Lunda) & Balunda \\
\hline Nkundu/Lonkundo (Mongo-Nkundu) & Mongo \\
\hline Nuer & Nuer \\
\hline Nyakyusa-Ngonde & Nyakyusa-Ngonde \\
\hline Nyoro & Banyoro \\
\hline Nzema & Akan \\
\hline Ondonga (Ndonga) & Ovambo \\
\hline Otoro & Nubians \\
\hline Pangwe/Pahouian (Fang) & Fang \\
\hline Rwanda/Ruanda (Hutus and Tutsis) & Banyaruanda \\
\hline Tsonga (Thonga) & Tsonga \\
\hline Umbundu/Mbunda/ Ovimbundu & Ovimbundu \\
\hline Wawihé/Viye & Wayeye \\
\hline Wolof/Woloff & Wolof \\
\hline Xun & Bushmen \\
\hline Yaka/Ba-Yaka & Bantu-speaking Pygmy tribes \\
\hline Yoruba & Yoruba \\
\hline Zande/Azande/Sandeh & Azande \\
\hline Zulu & Zulus \\
\hline
\end{tabular}

Note: *We were not able to match Bamhara ethnic group. However, according to Murray and Roscoe (1998), it is located in the current territory of the Democratic Republic of Kongo, that is not part of the Afrobarometer's sample. 
Table C.2: Summary statistics

\begin{tabular}{lcccc}
\hline \hline Variable & Mean & St.dev. & Min & Max \\
\cline { 2 - 5 } Strongly dislike homosexuals & 0.68 & 0.46 & 0 & 1 \\
Dislike or somewhat dislike homosexuals & 0.77 & 0.42 & 0 & 1 \\
Dislike homosexuals (ordinal) & 3.36 & 1.07 & 0 & 4 \\
Min. distance-to-mission, 100 km & 1.26 & 2.02 & 0.001 & 14.6 \\
Age & 37.09 & 14.83 & 0 & 105 \\
Female & 0.50 & 0.50 & 0 & 1 \\
Urban & 0.40 & 0.49 & 0 & 1 \\
\hline
\end{tabular}

Note: The data is from the 6th Afrobarometer wave. 33 countries, 50,337 observations. 
Table C.3: Additional robustness checks: Alternative clustering

\begin{tabular}{|c|c|c|c|c|c|c|}
\hline & $\overline{\mathrm{I}}$ & 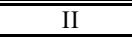 & III & IV & $\overline{\mathrm{V}}$ & 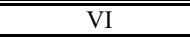 \\
\hline \multicolumn{7}{|c|}{ Dependent variable: Dislike homosexuals } \\
\hline \multirow{3}{*}{ Min. distance-to-mission, $100 \mathrm{~km}$} & $\begin{array}{c}\text { Baseline } \\
\text { (village/town } \\
\text { location) }\end{array}$ & $\begin{array}{l}\text { By country } \\
(\text { GADM } 0)\end{array}$ & $\begin{array}{c}\text { By province/state } \\
\text { (GADM 1) }\end{array}$ & $\begin{array}{l}\text { By sumbantional } \\
\text { regions (GADM 2) }\end{array}$ & $\begin{array}{c}\text { Double-clustered } \\
\text { by location and } \\
\text { ethnicity }\end{array}$ & $\begin{array}{c}\text { Double-clustered } \\
\text { by location and } \\
\text { country }\end{array}$ \\
\hline & $-0.013 * * *$ & $-0.013^{*}$ & $-0.013^{* *}$ & $-0.013 * *$ & $-0.013 * * *$ & $-0.013^{*}$ \\
\hline & $(0.0038)$ & $(0.0069)$ & $(0.0056)$ & $(0.0057)$ & $(0.0050)$ & $(0.0069)$ \\
\hline R-squared & 0.282 & 0.282 & 0.282 & 0.282 & 0.282 & 0.282 \\
\hline Observations & 50,337 & 50,337 & 50,337 & 50,337 & 50,337 & 50,337 \\
\hline
\end{tabular}

Note: (a) In all columns, we take the most demanding specification from the baseline results, i.e., Column V in Panel A of Table 1 but use different method of clustering standard errors. (b) In Column II, we cluster standard errors by country. In Column III, we cluster standard errors on province/state level. In Column IV we cluster by smaller administrative region. In Columns V and VI we double-cluster (Cameron, Gelbach and Miller, 2011) standard errors by the geographical unit and ethnicity and by gographical unit and country. ${ }^{* * *} \mathrm{p}<0.01,{ }^{* *} \mathrm{p}<0.05,{ }^{*} \mathrm{p}<0.1$ 
Table C.4: Main additional robustness checks

\begin{tabular}{|c|c|c|c|c|c|c|}
\hline & $\mathrm{I}$ & II & III & IV & $\mathrm{V}$ & VI \\
\hline & \multicolumn{6}{|c|}{ Dependent variable: Dislike homosexuals } \\
\hline & Baseline & $\begin{array}{c}\text { Only Sub- } \\
\text { Saharan } \\
\text { Africa }\end{array}$ & $\begin{array}{l}\text { Multi-country } \\
\text { sampling } \\
\text { weights }\end{array}$ & $\begin{array}{l}\text { Staple crops } \\
\text { suitability } \\
\text { controls }\end{array}$ & $\begin{array}{l}\text { Distance-to- } \\
\text { capital and } \\
\text { coast }\end{array}$ & $\begin{array}{l}\text { Location } \\
\text { ethnicity FEs }\end{array}$ \\
\hline $\begin{array}{l}\text { Min. distance-to-mission, } \\
100 \mathrm{~km}\end{array}$ & $\begin{array}{c}-0.013 * * * \\
(0.0038)\end{array}$ & $\begin{array}{c}-0.017 * * * \\
(0.0040)\end{array}$ & $\begin{array}{c}-0.013 * * * \\
(0.0045)\end{array}$ & $\begin{array}{c}-0.013 * * * \\
(0.0039)\end{array}$ & $\begin{array}{c}-0.016^{* * *} \\
(0.0041)\end{array}$ & $\begin{array}{c}-0.011 * * \\
(0.0042)\end{array}$ \\
\hline Multi-country sampl. weights & & & $\checkmark$ & & & \\
\hline Staple crops suitability controls & & & & $\checkmark$ & $\checkmark$ & $\checkmark$ \\
\hline Distances to capital and coast & & & & & $\checkmark$ & $\checkmark$ \\
\hline Location ethnicity FEs & & & & & & $\checkmark$ \\
\hline Respondent's ethnicity FEs & $\checkmark$ & $\checkmark$ & $\checkmark$ & $\checkmark$ & $\checkmark$ & $\checkmark$ \\
\hline R-squared & 0.282 & 0.294 & 0.281 & 0.282 & 0.284 & 0.297 \\
\hline Observations & 50,337 & 47,937 & 50,337 & 50,337 & 50,337 & 50,337 \\
\hline
\end{tabular}

Note: (a) In all columns, we take the most demanding specification from the baseline results, i.e., Column V in Panel A of Table 1. (b) In Column II, we estimate the specification for the subsample of Sub-Saharan countries, thus omitting all Maghrebian countries. (c) In Column III, we use Afrobarometer multi-country weights. (d) In other Columns we add additional controls. (e) Standard errors are clustered on the geographical unit level (town/village). ${ }^{* * *} \mathrm{p}<0.01,{ }^{* *} \mathrm{p}<0.05,{ }^{*} \mathrm{p}<0.1$ 
Table C.5: Additional robustness checks: Spatial HAC standard errors

\begin{tabular}{|c|c|c|c|c|c|c|}
\hline & $\mathrm{I}$ & II & III & IV & $\mathrm{V}$ & VI \\
\hline & $\begin{array}{c}\text { Spatial HAC } \\
(50 \mathrm{~km} \\
\text { cutoff })\end{array}$ & $\begin{array}{c}\text { Spatial HAC } \\
\text { (150 km } \\
\text { cutoff) }\end{array}$ & $\begin{array}{c}\text { Spatial HAC } \\
(300 \mathrm{~km} \\
\text { cutoff })\end{array}$ & $\begin{array}{c}\text { Spatial HAC } \\
\text { (500 km } \\
\text { cutoff) }\end{array}$ & $\begin{array}{c}\text { Spatial HAC } \\
(1,000 \mathrm{~km} \\
\text { cutoff })\end{array}$ & $\begin{array}{c}\text { Spatial HAC } \\
(1,500 \mathrm{~km} \\
\text { cutoff })\end{array}$ \\
\hline $\begin{array}{l}\text { Min. distance-to-mission, } \\
100 \mathrm{~km}\end{array}$ & $\begin{array}{c}-0.013 * * * \\
(0.0047)\end{array}$ & $\begin{array}{c}-0.013 * * * \\
(0.0051)\end{array}$ & $\begin{array}{c}-0.013 * * \\
(0.0056)\end{array}$ & $\begin{array}{c}-0.013 * * \\
(0.0062)\end{array}$ & $\begin{array}{l}-0.013^{*} \\
(0.0069)\end{array}$ & $\begin{array}{l}-0.013 * \\
(0.0072)\end{array}$ \\
\hline R-squared & 0.282 & 0.282 & 0.282 & 0.282 & 0.282 & 0.282 \\
\hline Observations & 50,337 & 50,337 & 50,337 & 50,337 & 50,337 & 50,337 \\
\hline
\end{tabular}

Note: (a) In all columns, we take the most demanding specification from the baseline results, i.e., Column V in Panel A of Table 1. The difference is that here we estimate spatial HAC standard errors (Conley, 2010) with different cutoffs. ${ }^{* * *} \mathrm{p}<0.01,{ }^{* *} \mathrm{p}<0.05,{ }^{*} \mathrm{p}<0.1$ 
Table C.6: Baseline results on the country-ethnicity level of aggregation

\begin{tabular}{|c|c|c|c|c|c|}
\hline & I & II & III & IV & $\mathrm{V}$ \\
\hline & \multicolumn{5}{|c|}{ Dependent variable: 1(Dislike homosexuals) } \\
\hline \multicolumn{6}{|l|}{ Panel A: baseline agg. on country-ethnicity } \\
\hline Aver. min. distance-to-mission, $100 \mathrm{~km}$ & $\begin{array}{c}-0.033 * * \\
(0.0166)\end{array}$ & $\begin{array}{c}-0.042 * * * \\
(0.0145)\end{array}$ & $\begin{array}{c}-0.043 * * * \\
(0.0145)\end{array}$ & $\begin{array}{c}-0.046 * * * \\
(0.0145)\end{array}$ & $\begin{array}{l}- \\
-\end{array}$ \\
\hline R-squared & 0.054 & 0.256 & 0.260 & 0.292 & \\
\hline Observations & 532 & 532 & 532 & 532 & \\
\hline Panel B: & \multicolumn{5}{|c|}{ Dependent variable: 1(Dislike or somewhat dislike homosexuals) } \\
\hline Aver. min. distance-to-mission, $100 \mathrm{~km}$ & $\begin{array}{c}-0.030 * * \\
(0.0142)\end{array}$ & $\begin{array}{c}-0.038 * * * \\
(0.0136)\end{array}$ & $\begin{array}{c}-0.039 * * * \\
(0.0135)\end{array}$ & $\begin{array}{c}-0.041 * * * \\
(0.0135)\end{array}$ & $\begin{array}{l}- \\
-\end{array}$ \\
\hline R-squared & 0.058 & 0.225 & 0.231 & 0.255 & \\
\hline Observations & 532 & 532 & 532 & 532 & \\
\hline Panel C: & \multicolumn{5}{|c|}{ Dependent variable: Dislike homosexuals (ordinal, from 0 to 4 ) } \\
\hline Aver. min. distance-to-mission, $100 \mathrm{~km}$ & $\begin{array}{c}-0.060 * * \\
(0.0301)\end{array}$ & $\begin{array}{c}-0.083 * * * \\
(0.0301)\end{array}$ & $\begin{array}{c}-0.086 * * * \\
(0.0299)\end{array}$ & $\begin{array}{c}-0.091 * * * \\
(0.0297)\end{array}$ & - \\
\hline R-squared & 0.037 & 0.230 & 0.233 & 0.259 & \\
\hline Observations & 532 & 532 & 532 & 532 & \\
\hline Country FEs & $\checkmark$ & $\checkmark$ & $\checkmark$ & $\checkmark$ & $\checkmark$ \\
\hline Modern geo. controls & & $\checkmark$ & $\checkmark$ & $\checkmark$ & $\checkmark$ \\
\hline Demographic controls & & & $\checkmark$ & $\checkmark$ & $\checkmark$ \\
\hline Urban dummy & & & & $\checkmark$ & $\checkmark$ \\
\hline Ethnicity FEs & & & & & $\checkmark$ \\
\hline
\end{tabular}

Note: (a) This Table replicates the baseline results from Panel A of Table 1 but uses country-ethnicity as the observation.(b) In parentheses we report robust clustered by country standard errors. ${ }^{* * *} \mathrm{p}<0.01,{ }^{* *} \mathrm{p}<0.05,{ }^{*} \mathrm{p}<0.1$ 


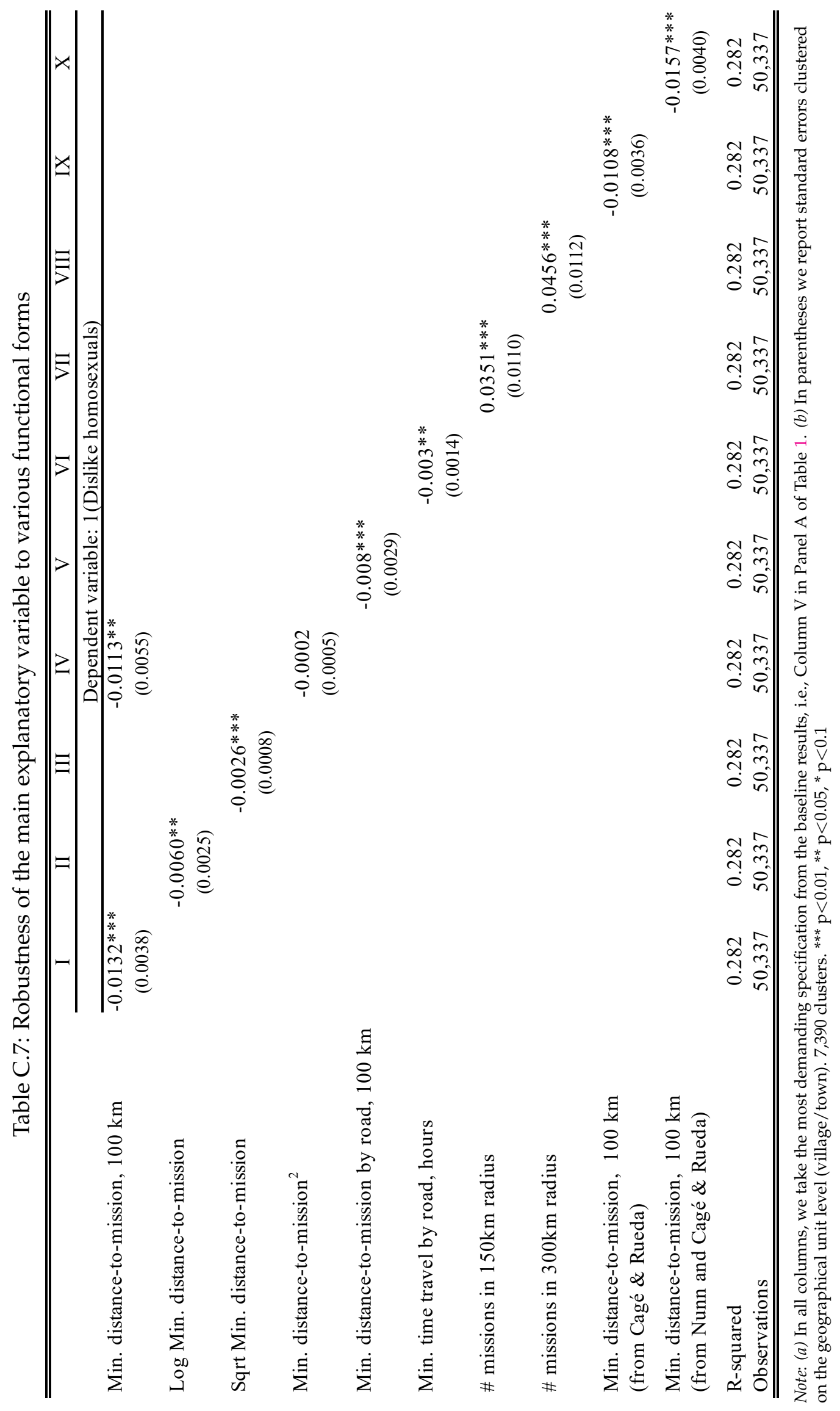


Table C.8: Replicating baseline results with seventh (2019) Afrobarometer wave

\begin{tabular}{|c|c|c|c|c|c|}
\hline \multirow{3}{*}{$\begin{array}{l}\text { Panel A: baseline with } 7 \text { th Afrobarometer wave } \\
\text { Min. distance-to-mission, } 100 \mathrm{~km}\end{array}$} & $\begin{array}{l}\mathrm{I} \\
\end{array}$ & $\overline{\mathrm{II}}$ & 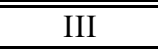 & $\overline{\mathrm{IV}}$ & $\mathrm{V}$ \\
\hline & \multicolumn{5}{|c|}{ Dependent variable: 1 (Dislike homosexuals) } \\
\hline & $\begin{array}{c}-0.006 * * \\
(0.0025)\end{array}$ & $\begin{array}{r}-0.005^{*} \\
(0.0027)\end{array}$ & $\begin{array}{r}-0.005^{*} \\
(0.0027)\end{array}$ & $\begin{array}{r}-0.005^{*} \\
(0.0027)\end{array}$ & $\begin{array}{l}-0.006^{*} \\
(0.0032)\end{array}$ \\
\hline $\begin{array}{l}\text { R-squared } \\
\text { Observations }\end{array}$ & $\begin{array}{c}0.268 \\
43,526 \\
\end{array}$ & $\begin{array}{c}0.270 \\
43,526 \\
\end{array}$ & $\begin{array}{c}0.270 \\
43,526 \\
\end{array}$ & $\begin{array}{c}0.270 \\
43,526 \\
\end{array}$ & $\begin{array}{c}0.290 \\
43,526 \\
\end{array}$ \\
\hline \multicolumn{6}{|l|}{ Panel B: $\sim 6$ th and 7 th Afrobarometer waves } \\
\hline Min. distance-to-mission, $100 \mathrm{~km}$ & $\begin{array}{l}-0.024 * * * \\
(0.0021)\end{array}$ & $\begin{array}{c}-0.016 * * * \\
(0.0019)\end{array}$ & $\begin{array}{c}-0.016 * * * \\
(0.0019)\end{array}$ & $\begin{array}{c}-0.019 * * * \\
(0.0019)\end{array}$ & $\begin{array}{c}-0.011 * * * \\
(0.0024)\end{array}$ \\
\hline $\begin{array}{l}\text { R-squared } \\
\text { Observations }\end{array}$ & $\begin{array}{r}0.250 \\
93,863 \\
\end{array}$ & $\begin{array}{r}0.258 \\
93,863 \\
\end{array}$ & $\begin{array}{c}0.260 \\
93,863 \\
\end{array}$ & $\begin{array}{c}0.261 \\
93,863 \\
\end{array}$ & $\begin{array}{c}0.284 \\
93,853 \\
\end{array}$ \\
\hline Country FEs & $\checkmark$ & $\checkmark$ & $\checkmark$ & $\checkmark$ & $\checkmark$ \\
\hline Modern geo. controls & & $\checkmark$ & $\checkmark$ & $\checkmark$ & $\checkmark$ \\
\hline Demographic controls & & & $\checkmark$ & $\checkmark$ & $\checkmark$ \\
\hline Urban dummy & & & & $\checkmark$ & $\checkmark$ \\
\hline Ethnicity FEs & & & & & $\checkmark$ \\
\hline
\end{tabular}

Note: (a) This Table replicates the baseline results from Panel A of Table 1 but uses seventh wave of Afrobarometer. (b) Panel A uses only seventh wafe of Afrobarometer. Panel B includes both, sixth and seventh waves. All columns in Panel B include a dummy for the seventh wave.(c) In parentheses we report standard errors clustered on the geographical unit level (village/town). ${ }^{* * *} \mathrm{p}<0.01,{ }^{* *}$ $\mathrm{p}<0.05,{ }^{*} \mathrm{p}<0.1$ 
Table C.9: Ancestral homosexual practices do not correlate with anti-gay attitudes today and with distance to missions: ethnic homelands level

\begin{tabular}{|c|c|c|c|c|c|c|}
\hline & $\mathrm{I}$ & II & III & IV & $\mathrm{V}$ & VI \\
\hline Panel A: & \multicolumn{6}{|c|}{ Dependent variable: Dislike homosexuals } \\
\hline $\begin{array}{l}\text { Ancestral norms allowed same- } \\
\text { sex relations }\end{array}$ & $\begin{array}{c}0.044 \\
(0.0358)\end{array}$ & $\begin{array}{c}0.012 \\
(0.0350)\end{array}$ & $\begin{array}{c}0.003 \\
(0.0332)\end{array}$ & $\begin{array}{c}0.028 \\
(0.0410)\end{array}$ & $\begin{array}{c}0.036 \\
(0.0380)\end{array}$ & $\begin{array}{c}0.038 \\
(0.0445)\end{array}$ \\
\hline $\begin{array}{l}\text { Modern geo. controls } \\
\text { Ancestral geo. controls } \\
\text { Moralizing god } \\
\text { Ancestral marital norms }\end{array}$ & & $\checkmark$ & $\begin{array}{l}\checkmark \\
\checkmark\end{array}$ & $\begin{array}{l}\checkmark \\
\checkmark\end{array}$ & $\checkmark$ & $\begin{array}{l}\checkmark \\
\checkmark \\
\checkmark \\
\checkmark\end{array}$ \\
\hline $\begin{array}{l}\text { R-squared } \\
\text { Observations }\end{array}$ & $\begin{array}{c}0.079 \\
381 \\
\end{array}$ & $\begin{array}{c}0.117 \\
381 \\
\end{array}$ & $\begin{array}{c}0.256 \\
381 \\
\end{array}$ & $\begin{array}{c}0.138 \\
381 \\
\end{array}$ & $\begin{array}{c}0.141 \\
381 \\
\end{array}$ & $\begin{array}{c}0.290 \\
381 \\
\end{array}$ \\
\hline Panel B: & \multicolumn{6}{|c|}{ Dependent variable: Mission density (\# missions/area) } \\
\hline $\begin{array}{l}\text { Ancestral norms allowed same- } \\
\text { sex relations }\end{array}$ & $\begin{array}{c}0.005 \\
(0.2827)\end{array}$ & $\begin{array}{l}-0.385 \\
(0.2878)\end{array}$ & $\begin{array}{l}-0.295 \\
(0.2373)\end{array}$ & $\begin{array}{l}-0.232 \\
(0.3700)\end{array}$ & $\begin{array}{l}-0.307 \\
(0.3269)\end{array}$ & $\begin{array}{l}-0.256 \\
(0.3312)\end{array}$ \\
\hline $\begin{array}{l}\text { Modern geo. controls } \\
\text { Ancestral geo. controls } \\
\text { Moralizing god } \\
\text { Ancestral marital norms }\end{array}$ & & $\checkmark$ & $\begin{array}{l}\checkmark \\
\checkmark\end{array}$ & $\begin{array}{l}\checkmark \\
\checkmark\end{array}$ & $\checkmark$ & $\begin{array}{l}\checkmark \\
\checkmark \\
\checkmark \\
\checkmark\end{array}$ \\
\hline $\begin{array}{l}\text { R-squared } \\
\text { Observations }\end{array}$ & $\begin{array}{c}0.015 \\
381\end{array}$ & $\begin{array}{c}0.122 \\
381\end{array}$ & $\begin{array}{c}0.318 \\
381\end{array}$ & $\begin{array}{c}0.176 \\
381\end{array}$ & $\begin{array}{c}0.137 \\
381\end{array}$ & $\begin{array}{c}0.442 \\
381\end{array}$ \\
\hline
\end{tabular}

Note: (a) This Table replicates Table 2 but uses ethnic homelands level as observation instead of a respondent. (b) In parentheses we report robust standard errors. ${ }^{* * *} \mathrm{p}<0.01,{ }^{* *} \mathrm{p}<0.05,{ }^{*} \mathrm{p}<0.1$ 
Table C.10: Replication of Table 2 on subsamples of large and small ethnolinguistic groups

\begin{tabular}{|c|c|c|c|c|c|c|}
\hline & $\mathrm{I}$ & II & III & IV & $\mathrm{V}$ & VI \\
\hline Panel A: $\sim$ Small ethnic groups (<median) & \multicolumn{6}{|c|}{ Dependent variable: Dislike homosexuals } \\
\hline Ancestral norms allowed same-sex relations & $\begin{array}{c}0.009 \\
(0.0184)\end{array}$ & $\begin{array}{c}0.010 \\
(0.0184)\end{array}$ & $\begin{array}{c}0.010 \\
(0.0184)\end{array}$ & $\begin{array}{c}0.020 \\
(0.0291)\end{array}$ & $\begin{array}{c}0.009 \\
(0.0202)\end{array}$ & $\begin{array}{c}0.020 \\
(0.0308)\end{array}$ \\
\hline $\begin{array}{l}\text { R-squared } \\
\text { Observations }\end{array}$ & $\begin{array}{c}0.216 \\
25,194\end{array}$ & $\begin{array}{c}0.216 \\
25,194\end{array}$ & $\begin{array}{c}0.216 \\
25,194\end{array}$ & $\begin{array}{c}0.152 \\
14,733\end{array}$ & $\begin{array}{c}0.211 \\
21,564\end{array}$ & $\begin{array}{c}0.147 \\
13,207\end{array}$ \\
\hline $\begin{array}{l}\text { Panel B: } \sim \text { Large ethnic groups ( } \geq \text { median) } \\
\text { Ancestral norms allowed same-sex relations }\end{array}$ & $\begin{array}{c}0.108 \\
(0.0900)\end{array}$ & $\begin{array}{c}0.110 \\
(0.0873)\end{array}$ & $\begin{array}{c}0.110 \\
(0.0876)\end{array}$ & $\begin{array}{c}0.123 \\
(0.0955)\end{array}$ & $\begin{array}{c}0.126 \\
(0.0971)\end{array}$ & $\begin{array}{c}0.123 \\
(0.0955)\end{array}$ \\
\hline $\begin{array}{l}\text { R-squared } \\
\text { Observations }\end{array}$ & $\begin{array}{c}0.247 \\
25,143\end{array}$ & $\begin{array}{c}0.249 \\
25,143\end{array}$ & $\begin{array}{c}0.252 \\
23,947 \\
\end{array}$ & $\begin{array}{c}0.182 \\
17,984 \\
\end{array}$ & $\begin{array}{c}0.233 \\
22,375\end{array}$ & $\begin{array}{c}0.182 \\
17,984 \\
\end{array}$ \\
\hline Panel C: $\sim$ Small ethnic groups (<median) & \multicolumn{6}{|c|}{ Dependent variable: Min. distance-to-mission, $100 \mathrm{~km}$} \\
\hline Ancestral norms allowed same-sex relations & $\begin{array}{l}-0.019 \\
(0.0471)\end{array}$ & $\begin{array}{l}-0.016 \\
(0.0475)\end{array}$ & $\begin{array}{l}-0.016 \\
(0.0475)\end{array}$ & $\begin{array}{l}-0.001 \\
(0.0679)\end{array}$ & $\begin{array}{l}-0.012 \\
(0.0527)\end{array}$ & $\begin{array}{l}-0.004 \\
(0.0724)\end{array}$ \\
\hline $\begin{array}{l}\text { R-squared } \\
\text { Observations }\end{array}$ & $\begin{array}{c}0.873 \\
25,194 \\
\end{array}$ & $\begin{array}{c}0.873 \\
25,194 \\
\end{array}$ & $\begin{array}{c}0.873 \\
25,194 \\
\end{array}$ & $\begin{array}{c}0.888 \\
14,733 \\
\end{array}$ & $\begin{array}{c}0.858 \\
21,564 \\
\end{array}$ & $\begin{array}{c}0.878 \\
13,207 \\
\end{array}$ \\
\hline Panel D: $\sim$ Large ethnic groups $(\geq$ median $)$ & & & & & & \\
\hline Ancestral norms allowed same-sex relations & $\begin{array}{l}-1.617 \\
(1.1399)\end{array}$ & $\begin{array}{l}-1.592 \\
(1.0854)\end{array}$ & $\begin{array}{l}-1.591 \\
(1.0865)\end{array}$ & $\begin{array}{l}-1.787 \\
(1.1978)\end{array}$ & $\begin{array}{c}-1.788 \\
(1.1989)\end{array}$ & $\begin{array}{l}-1.787 \\
(1.1978)\end{array}$ \\
\hline $\begin{array}{l}\text { R-squared } \\
\text { Observations }\end{array}$ & $\begin{array}{c}0.694 \\
25,143\end{array}$ & $\begin{array}{c}0.696 \\
25,143\end{array}$ & $\begin{array}{c}0.690 \\
23,947\end{array}$ & $\begin{array}{c}0.625 \\
17,984\end{array}$ & $\begin{array}{c}0.692 \\
22,375\end{array}$ & $\begin{array}{c}0.625 \\
17,984\end{array}$ \\
\hline $\begin{array}{l}\text { Modern geo. controls } \\
\text { Ancestral geo. controls } \\
\text { Moralizing god } \\
\text { Ancestral marital norms }\end{array}$ & & $\checkmark$ & $\begin{array}{l}\checkmark \\
\checkmark\end{array}$ & $\checkmark$ & $\checkmark$ & $\begin{array}{l}\checkmark \\
\checkmark \\
\checkmark \\
\checkmark\end{array}$ \\
\hline
\end{tabular}

Note: (a) Panels A and C replicate Panels A and B of Table 2, respectively, on the subsample of the smallest ethnic groups. Panels B and $D$ replicate Panels A and B of Table 2, respectively, on the subsample of the largest ethnic groups. (b) In parentheses we report standard errors clustered on the geographical unit level (village/town). ${ }^{* * *} \mathrm{p}<0.01,{ }^{* *} \mathrm{p}<0.05,{ }^{*} \mathrm{p}<0.1$ 
Table C.11: Distance to historical missions does not correlate with cash crops and malaria ecology

\begin{tabular}{|c|c|c|c|c|c|c|}
\hline & $\mathrm{I}$ & II & III & IV & $\mathrm{V}$ & VI \\
\hline & \multicolumn{6}{|c|}{ Dependent variable: } \\
\hline & \multicolumn{3}{|c|}{ Dislike homosexuals } & \multicolumn{3}{|c|}{ Min.distance-to-mission, $100 \mathrm{~km}$} \\
\hline $\begin{array}{l}\text { Ancestral norms allowed same-sex } \\
\text { relations }\end{array}$ & $\begin{array}{c}0.041 \\
(0.0318)\end{array}$ & $\begin{array}{c}0.026 \\
(0.0230)\end{array}$ & $\begin{array}{c}0.057 \\
(0.0453)\end{array}$ & $\begin{array}{l}-0.590 \\
(0.4081)\end{array}$ & $\begin{array}{l}-0.296 \\
(0.2090)\end{array}$ & $\begin{array}{l}-0.757 \\
(0.5733)\end{array}$ \\
\hline Cocoa suitability & $\checkmark$ & & & $\checkmark$ & & \\
\hline Palm suitability & $\checkmark$ & & & $\checkmark$ & & \\
\hline w/o kola nut countries & & $\checkmark$ & & & $\checkmark$ & \\
\hline Malaria temperature suitability & & & $\checkmark$ & & & $\checkmark$ \\
\hline Plasmodium falciparum days & & & $\checkmark$ & & & $\checkmark$ \\
\hline Plasmodium vivax days & & & $\checkmark$ & & & $\checkmark$ \\
\hline R-squared & 0.284 & 0.299 & 0.284 & 0.284 & 0.284 & 0.284 \\
\hline Observations & 49,141 & 44,342 & 49,142 & 49,142 & 49,142 & 49,142 \\
\hline
\end{tabular}

Note: (a) This Table replicates Column VI of both Panels of Table 2 but with additional controls in Columns I, III, IV, and V. In Columns II and V it omits countries where kola nuts grow: Liberia, Niger, Nigeria, and Sierra Leone. (b) In parentheses we report standard errors clustered on the geographical unit level (village/town). ${ }^{* * *} \mathrm{p}<0.01,{ }^{* *} \mathrm{p}<0.05,{ }^{*} \mathrm{p}<0.1$ 
Table C.12: Robustness to cash crops and malaria controls

\begin{tabular}{|c|c|c|c|c|c|c|c|}
\hline & $\mathrm{I}$ & II & III & IV & $\mathrm{V}$ & $\overline{\mathrm{VI}}$ & VII \\
\hline & \multicolumn{7}{|c|}{ Dependent variable: Dislike homosexuals } \\
\hline Sample & All & $\begin{array}{c}\text { No kola } \\
\text { countries }\end{array}$ & & & All & & \\
\hline $\begin{array}{l}\text { Min. distance-to-mission, } \\
100 \mathrm{~km}\end{array}$ & $\begin{array}{c}-0.012 * * * \\
(0.0038)\end{array}$ & $\begin{array}{c}-0.011 * * * \\
(0.0041)\end{array}$ & $\begin{array}{c}-0.013 * * * \\
(0.0039)\end{array}$ & $\begin{array}{c}-0.013 * * * \\
(0.0039)\end{array}$ & $\begin{array}{c}-0.013 * * * \\
(0.0039)\end{array}$ & $\begin{array}{c}-0.013 * * * \\
(0.0039)\end{array}$ & $\begin{array}{c}-0.012 * * * \\
(0.0038)\end{array}$ \\
\hline Cocoa suitability & $\begin{array}{l}-0.004 \\
(0.0037)\end{array}$ & & & & & & $\begin{array}{l}-0.004 \\
(0.0037)\end{array}$ \\
\hline Palm suitability & $\begin{array}{l}-0.007 \\
(0.0050)\end{array}$ & & & & & & $\begin{array}{l}-0.007 \\
(0.0050)\end{array}$ \\
\hline $\begin{array}{l}\text { Plasmodium vivax and falciparum } \\
\text { temp. suitability }\end{array}$ & & & $\begin{array}{c}0.001 \\
(0.0025)\end{array}$ & & & $\begin{array}{l}-0.036 \\
(0.0727)\end{array}$ & $\begin{array}{l}-0.048 \\
(0.0722)\end{array}$ \\
\hline Plasmodium falciparum days & & & & $\begin{array}{c}0.001 \\
(0.0025)\end{array}$ & & $\begin{array}{l}-0.065 \\
(0.0699)\end{array}$ & $\begin{array}{l}-0.073 \\
(0.0699)\end{array}$ \\
\hline Plasmodium vivax days & & & & & $\begin{array}{c}0.002 \\
(0.0025)\end{array}$ & $\begin{array}{c}0.103 \\
(0.0919)\end{array}$ & $\begin{array}{c}0.123 \\
(0.0922)\end{array}$ \\
\hline R-squared & 0.284 & 0.299 & 0.284 & 0.284 & 0.284 & 0.284 & 0.284 \\
\hline Observations & 49,141 & 44,342 & 49,142 & 49,142 & 49,142 & 49,142 & 49,142 \\
\hline
\end{tabular}

Note: (a) In all columns, we take specification with ethnicity fixed effects from the baseline results, i.e., Column VI in Panel A of Table 1 but with additional controls. (b) In parentheses we report standard errors clustered on the geographical unit level (village/town). ${ }^{* * *}$ $\mathrm{p}<0.01,{ }^{* *} \mathrm{p}<0.05,{ }^{*} \mathrm{p}<0.1$ 
Table C.13: Robustness to socio-economic characteristics of respondents

\begin{tabular}{|c|c|c|c|c|c|c|c|c|}
\hline & $\bar{I}$ & $\overline{\text { III }}$ & $\overline{\text { III }}$ & 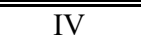 & $\overline{\mathrm{V}}$ & $\overline{\mathrm{VI}}$ & $\begin{array}{l}\text { VII } \\
\end{array}$ & VIII \\
\hline & \multicolumn{8}{|c|}{ Dependent variable: Dislike homosexuals } \\
\hline $\begin{array}{l}\text { Min. distance-to-mission, } \\
100 \mathrm{~km}\end{array}$ & $\begin{array}{c}-0.0132 * * * \\
(0.0038)\end{array}$ & $\begin{array}{c}-0.013 * * * \\
(0.0038)\end{array}$ & $\begin{array}{c}-0.013 * * * \\
(0.0038)\end{array}$ & $\begin{array}{c}-0.014 * * * \\
(0.0038)\end{array}$ & $\begin{array}{c}-0.015 * * * \\
(0.0038)\end{array}$ & $\begin{array}{c}-0.015^{* * *} \\
(0.0039)\end{array}$ & $\begin{array}{c}-0.013 * * * \\
(0.0038)\end{array}$ & $\begin{array}{c}-0.016 * * * \\
(0.0038)\end{array}$ \\
\hline Good living conditions & & $\begin{array}{c}-0.015^{* * *} \\
(0.0045)\end{array}$ & & & & & & $\begin{array}{l}-0.008 * \\
(0.0048)\end{array}$ \\
\hline Support for democracy & & & $\begin{array}{c}0.002 \\
(0.0043)\end{array}$ & & & & & $\begin{array}{c}0.006 \\
(0.0043)\end{array}$ \\
\hline Household assets FEs & & & & $\checkmark$ & & & & $\checkmark$ \\
\hline Public goods FEs & & & & & $\checkmark$ & & & $\checkmark$ \\
\hline Education FEs & & & & & & $\checkmark$ & & $\checkmark$ \\
\hline Employment FEs & & & & & & & $\checkmark$ & $\checkmark$ \\
\hline R-squared & 0.282 & 0.282 & 0.282 & 0.282 & 0.285 & 0.284 & 0.282 & 0.287 \\
\hline Observations & 50,337 & 50,337 & 50,337 & 50,337 & 50,337 & 50,337 & 50,337 & 50,337 \\
\hline
\end{tabular}

Note: (a) In all columns, we take the most demanding specification from the baseline results, i.e., Column VII in Panel A of Table 1. (b) Household assets include dummies for the ownership of radio, car/motorcycle, TV, and mobile phone. Public goods fixed effect include dummies for electricity, toilet type, and water access. (c) In parentheses we report standard errors clustered on the geographical unit level (village/town). ${ }^{* * *} \mathrm{p}<0.01,{ }^{* *} \mathrm{p}<0.05,{ }^{*} \mathrm{p}<0.1$ 
Table C.14: Additional alternative explanations: poverty, HIV, and polygyny

\begin{tabular}{|c|c|c|c|c|c|c|c|}
\hline & I & II & III & IV & $\mathrm{V}$ & VI & VII \\
\hline & \multicolumn{7}{|c|}{ Dependent variable: Dislike homosexuals } \\
\hline Sample & & Baseline (all) & & HIV $>1.5 \%$ & $\mathrm{HIV} \leq 1.5 \%$ & $\begin{array}{c}\text { Share of } \\
\text { polygamous } \\
\text { hh. }>32 \%\end{array}$ & $\begin{array}{c}\text { Share of } \\
\text { polygamous hh } \\
\leq 32 \%\end{array}$ \\
\hline $\begin{array}{r}\text { Min. distance-to-mission } \\
100 \mathrm{~km}\end{array}$ & $\begin{array}{c}-0.0132 * * * \\
(0.0038)\end{array}$ & $\begin{array}{l}-0.017 * * * \\
(0.0039)\end{array}$ & $\begin{array}{c}-0.014 * * * \\
(0.0039)\end{array}$ & $\begin{array}{c}-0.017 * * * \\
(0.0065)\end{array}$ & $\begin{array}{l}-0.010^{* *} \\
(0.0049)\end{array}$ & $\begin{array}{c}-0.011^{* *} \\
(0.0047)\end{array}$ & $\begin{array}{l}-0.017 * * \\
(0.0069)\end{array}$ \\
\hline Night light luminosity & & $\begin{array}{c}-0.001 * * * \\
(0.0002)\end{array}$ & & & & & \\
\hline Log population density & & & $\begin{array}{l}-0.001 \\
(0.0011)\end{array}$ & & & & \\
\hline R-squared & 0.282 & 0.283 & 0.282 & 0.264 & 0.323 & 0.231 & 0.330 \\
\hline Observations & 50,337 & 50,337 & 50,337 & 35,937 & 14,400 & 27,551 & 22,786 \\
\hline
\end{tabular}

Note: (a) In all columns, we take the most demanding specification from the baseline results, i.e., Column VII in Panel A of Table 1. (b) In Columns IV and V, we estimate the specification for the subsample of countries where HIV rate is above and below the mean of countries in our sample. (c) In Columns VI and VI, we estimate the specification for the subsample of countries where share of polygamous households is above and below the mean of countries in our sample. (d) In parentheses we report standard errors clustered on the geographical unit level (village/town). ${ }^{* * *} \mathrm{p}<0.01,{ }^{* *} \mathrm{p}<0.05,{ }^{*} \mathrm{p}<0.1$ 
Table C.15: Distance to historical missions and alternative outcomes

\begin{tabular}{lcccc}
\hline \hline & \multicolumn{2}{c}{ I } & III & IV \\
\cline { 2 - 5 } & \multicolumn{4}{c}{ Dependent variable: Dislike } \\
\cline { 2 - 5 } & $\begin{array}{c}\text { People of } \\
\text { different } \\
\text { religions }\end{array}$ & $\begin{array}{c}\text { People of } \\
\text { different } \\
\text { ethnicities }\end{array}$ & $\begin{array}{c}\text { People with } \\
\text { HIV/AIDS }\end{array}$ & $\begin{array}{c}\text { Immigrants } \\
\text { and foreign } \\
\text { workers }\end{array}$ \\
\cline { 2 - 5 } Min. distance-to-mission, 100km & 0.001 & -0.003 & -0.0004 & -0.004 \\
R-squared & $(0.0023)$ & $(0.0016)$ & $(0.0044)$ & $(0.0026)$ \\
Observations & 0.133 & 0.058 & 0.233 & 0.059 \\
\hline
\end{tabular}

Note: (a) In all columns, we take the most demanding specification from the baseline results, i.e., Column $\mathrm{V}$ in Panel A of Table 1. but with different outcomes. (b) The dependent variable is equal to one if respondents strongly dislikes to be a neighbor with people of different religions (Column I), people of different ethnicities (Column II), people with HIV/AIDS (Column III), and immigrants and foreign workers (Column IV). (c) In parentheses we report standard errors clustered on the geographical unit level (village/town). 7,390 clusters. ${ }^{* * *} \mathrm{p}<0.01,{ }^{* *} \mathrm{p}<0.05,{ }^{*} \mathrm{p}<0.1$ 
Table C.16: No (statistically significant) differential effects in countries with and without British colonial presence

\begin{tabular}{|c|c|c|c|}
\hline & $\mathrm{I}$ & II & III \\
\hline & \multicolumn{3}{|c|}{ Dependent variable: Dislike homosexuals } \\
\hline Sample & $\begin{array}{l}\text { Countries without } \\
\text { British presence }\end{array}$ & $\begin{array}{l}\text { Countries with } \\
\text { British presence }\end{array}$ & All \\
\hline Min. distance-to-mission, $100 \mathrm{~km}$ & $\begin{array}{c}-0.010 * * \\
(0.0043)\end{array}$ & $\begin{array}{c}-0.023 * * * \\
(0.0084)\end{array}$ & $\begin{array}{c}-0.011 * * * \\
(0.0043)\end{array}$ \\
\hline $\begin{array}{l}\text { Min. distance-to-mission, } 100 \mathrm{~km} \\
\text { x British presence }\end{array}$ & & & $\begin{array}{l}-0.008 \\
(0.0087)\end{array}$ \\
\hline R-squared & 0.319 & 0.244 & 0.282 \\
\hline Observations & 25,192 & 25,145 & 50,337 \\
\hline
\end{tabular}

Note: (a) In all columns, we take the most demanding specification from the baseline results, i.e., Column V in Panel A of Table 1. Dummy for British presence is equal to one if a country had British colonial presence. These countries are: Benin, Cameroon, Eswatini, Ghana, Kenya, Lesotho, Namibia, Nigeria, Sierra Leone, South Africa, Tanzania, Uganda, Zambia, and Zimbabwe. (b) In parentheses we report standard errors clustered on the geographical unit level (village/town). 7,390 clusters. ${ }^{* * *} \mathrm{p}<0.01,{ }^{* *} \mathrm{p}<0.05,{ }^{*} \mathrm{p}<0.1$ 
Table C.17: No (statistically significant) differential effects on rural and urban respondents

\begin{tabular}{|c|c|c|c|}
\hline \multirow[b]{3}{*}{ Min. distance-to-mission, $100 \mathrm{~km}$} & I & II & III \\
\hline & \multicolumn{3}{|c|}{ Dependent variable: Dislike homosexuals } \\
\hline & $\begin{array}{c}-0.013 * * * \\
(0.0038)\end{array}$ & & \\
\hline $\begin{array}{r}\text { Min. distance-to-mission, } 100 \mathrm{~km} \\
\mathrm{x} \text { urban }\end{array}$ & & $\begin{array}{c}-0.016^{* * *} \\
(0.0047)\end{array}$ & $\begin{array}{c}-0.025 * * * \\
(0.0068)\end{array}$ \\
\hline $\begin{array}{l}\text { Min. distance-to-mission, } 100 \mathrm{~km} \\
\mathrm{x} \text { rural }\end{array}$ & & $\begin{array}{c}-0.012 * * * \\
(0.0039)\end{array}$ & $\begin{array}{l}-0.008 * \\
(0.0045)\end{array}$ \\
\hline Ethnicity and urban FEs & $\checkmark$ & $\checkmark$ & \\
\hline Ethnicity x urban FEs & & & $\checkmark$ \\
\hline R-squared & 0.282 & 0.282 & 0.290 \\
\hline Observations & 50,337 & 50,337 & 50,337 \\
\hline
\end{tabular}

Note: (a) In all columns, we take the most demanding specification from the baseline results, i.e., Column VII in Panel A of Table 1. (b) Columns II and III report on the specification (1) but replaces $\beta \cdot$ Distance $_{c m}$ with $\beta^{U} \cdot$ Distance $_{c m} \cdot 1$ (Urban) and $\beta^{R} \cdot$ Distance Dim $_{\text {ist }}$. 1 (Rural). (c) Column III includes set of ethnicity fixed effects interacted with urban dummy instead of a set of ethnicity fixed effects and an urban dummy in Columns I-II. (d) In parentheses we report standard errors clustered on the geographical unit level (village/town). ${ }^{* * *} \mathrm{p}<0.01,{ }^{* *} \mathrm{p}<0.05,{ }^{*} \mathrm{p}<0.1$ 
Table C.18: Gender norms

\begin{tabular}{lcc}
\hline \hline & \multicolumn{2}{c}{ I } \\
\cline { 2 - 3 } & \multicolumn{2}{c}{ Dependent variable: } \\
\cline { 2 - 3 } & $\begin{array}{c}\text { Women are OK as } \\
\text { leaders }\end{array}$ & $\begin{array}{c}\text { Women are OK as } \\
\text { leaders (alt.) }\end{array}$ \\
\cline { 2 - 3 } Min. distance-to-mission, 100km & 0.0023 & -0.0015 \\
& $(0.0027)$ & $(0.0035)$ \\
R-squared & 0.068 & 0.055 \\
Observations & 50,337 & 50,337 \\
\hline \hline
\end{tabular}

Note: (a) In all columns, we take the most demanding specification from the baseline results, i.e., Column V in Panel A of Table 1. (b) In Column I the dependent variable is a dummy equal to 1 , if the respondent strongly believe that women can be a leader. In Column II the dependent variable is a dummy equal to 1 , if the respondent strongly believe or somewhat believe that women can be a leader. (c) In parentheses we report standard errors clustered on the geographical unit level (village/town). ${ }^{* * *} \mathrm{p}<0.01,{ }^{* *} \mathrm{p}<0.05,{ }^{*} \mathrm{p}<0.1$ 
Table C.19: Distance to historical missions spread Christianity

\begin{tabular}{lccccc}
\hline \hline & \multicolumn{1}{c}{ I } & II & III & IV \\
\cline { 2 - 6 } & \multicolumn{3}{c}{ Dependent variable: 1(Any Christian denomination) } \\
\cline { 2 - 6 } Min. distance-to-mission, $100 \mathrm{~km}$ & $-0.029 * * *$ & $-0.018^{* *}$ & $-0.018^{* *}$ & $-0.017 * *$ & $-0.010^{* * *}$ \\
& $(0.0061)$ & $(0.0078)$ & $(0.0078)$ & $(0.0079)$ & $(0.0030)$ \\
R-squared & 0.385 & 0.398 & 0.399 & 0.399 & 0.548 \\
Observations & 50,321 & 50,321 & 50,321 & 50,321 & 50,321 \\
\hline Country FEs & $\checkmark$ & $\checkmark$ & $\checkmark$ & $\checkmark$ & $\checkmark$ \\
Modern geo. controls & & $\checkmark$ & $\checkmark$ & $\checkmark$ & $\checkmark$ \\
Demographic controls & & & $\checkmark$ & $\checkmark$ & $\checkmark$ \\
Urban dummy & & & $\checkmark$ & $\checkmark$ \\
Ethnicity FEs & & & & $\checkmark$ \\
\hline
\end{tabular}

Note: (a) In this Table we replicate Panel A of Table 1 but with different outcome variable. $(b)$ In Column I the dependent variable is a dummy equal to 1 , if the respondent is a Christian (any denomination). (c) In parentheses we report standard errors clustered on the geographical unit level (village/town). ${ }^{* * *} \mathrm{p}<0.01,{ }^{* *} \mathrm{p}<0.05,{ }^{*} \mathrm{p}<0.1$ 
Table C.20: Spatial HAC with Matern kernel from Kelly (2020)

\begin{tabular}{lc}
\hline \hline Range & $20 \mathrm{~km}$ \\
Effective Range & $64 \mathrm{~km}$ \\
Moran Z & 10.1 \\
Smoothness & 0.05 \\
\hline Main coefficient & $-0.014^{* *}$ \\
HAC s.e. & 0.007 \\
HAC t-stat & -2.022 \\
Observations & 27685 \\
\hline
\end{tabular}

Note: The procedure uses our most demanding specification (Column V, Panel A of Table 1). The code for data preparation is taken is based on Morgan Kelly's replication of Nunn and Wantchekon (2011): https://rpubs.com/Morgan_Kelly/nunn_mistrust. The code for the spatial HAC calculation is taken is from Morgan Kelly's Github archive: https: //github.com/morganwkelly/ persistence from the zip file "Nunn_Mistrust.zip." For range candidates we used a sequence from 10 to $150 \mathrm{~km}$ with a step of 10. We used 55 percent random sample of our data for the calculation. 